\title{
Voltage-activated Calcium Currents in Identified Neurons from a Hydrozoan Jellyfish, Polyorchis penicillatus
}

\author{
Jan Przysiezniak and Andrew N. Spencer \\ Department of Zoology, University of Alberta, Edmonton, Alberta, Canada T6G 2E9 and Bamfield Marine Station, \\ Bamfield, British Columbia, Canada VOR 1B0
}

\begin{abstract}
Calcium currents were studied in isolated "swim motor neurons" from the jellyfish Polyorchis penicillatus, using the tight-seal, whole-cell, voltage-clamp technique. Two highvoltage-activated (HVA) currents were observed. The transient current, HVA-t, activated rapidly (time to peak, $4 \mathrm{msec}$ ), inactivated with two time constants (26 msec, $187 \mathrm{msec}$ ) in a positive voltage range $\left(V_{i}=-23 \mathrm{mV}\right)$, and was larger when carried by calcium than by barium ions. The sustained current, HVA-s, inactivated slowly or not at all, even at very positive voltages and had the same amplitude whether carried by $\mathrm{Ca}^{2+}$ or $\mathrm{Ba}^{2+}$. It is likely that the two HVA current components arise from distinct channel populations, because the ionic selectivity of calcium channels is not known to depend on their inactivation kinetics. A third current appeared to activate at very positive voltages, and at a slower rate than did HVA-t. It is likely to be an artifact of inhomogeneous space clamping. A low-voltage-activated, cadmium-insensitive calcium current may also be present. Calcium currents in this primitive, multicellular animal have properties similar to calcium currents in other phyla; however, they do not fit neatly into the " $T, N$, L" classification scheme of vertebrate calcium currents.
\end{abstract}

Nervous systems probably first evolved in close ancestors of the Cnidaria, when certain cells became specialized for electrical excitation and rapid chemical neurotransmission. The voltageclamp study of membrane ionic currents from these primitive animals is significant to comparative physiology since it can provide information on the molecular evolution of ion channel populations that paralleled the functional emergence of neurons. Calcium currents were studied in "swim motor neurons" (SMNs) isolated from the hydrozoan jellyfish Polyorchis penicillatus to identify characteristics that will help in describing the roles of these currents in excitability and synaptic function.

The SMNs of Polyorchis penicillatus have been described in situ both morphologically (Spencer, 1979) and electrophysiologically (Anderson and Mackie, 1977; Spencer, 1981), and their

\footnotetext{
Received July 9, 1991; revised Dec. 17, 1991; accepted Dec. 30, 1991

This work was supported by NSERC Operating Grant AO419 to A.N.S., an AHFMR studentship to J.P., and an NSERC postgraduate scholarship to J.P. We thank Drs. Andrew French, I isa Stockbridge, and Marek Duszyk for discussions on ion permeation; Dr. Norman L. Stockbridge for patient discussions on space clamping; Dr. Ebenezer Yamoah for helpful discussions; Ms. Lan Diep for help with ion chromatography and atomic absorption spectroscopy; and Ms. Dianne Formanski for carrying out the inductively coupled plasma spectroscopy. This report was completed in partial fulfillment of J.P.'s doctoral program.

Correspondence should be addressed to Dr. Andrew N. Spencer, Department of Zoology, University of Alberta, Edmonton, Alberta, Canada T6G 2E9.

Copyright (C) 1992 Society for Neuroscience $0270-6474 / 92 / 122065-14 \$ 05.00 / 0$
}

role in the control of swimming is established (Spencer, 1978, 1982; Satterlie and Spencer, 1983). These cells form an electrically coupled network around the bell margin (Spencer and Satterlie, 1980) that synapses onto the swimming muscle sheets (Spencer, 1979, 1982) and drives swimming. To circumvent the voltage-clamp problems associated with electrical coupling, a primary culture technique was recently developed for the isolation of the SMNs (Przysiezniak and Spencer, 1989).

In these SMNs, firing patterns and synaptic transmission probably depend on the influx of calcium ions, as demonstrated, respectively, by Anderson (1979) using ionic substitutions and by Spencer (1982) using $\mathrm{Mg}^{2+}$ blockade. However, more direct interventions are needed to understand the mechanisms of calcium influx in these cells. Tight-seal, whole-cell, voltage clamp has recently been used to describe calcium currents in various cnidarians (Anderson, 1987, in Cyanea; Dunlap et al., 1987, in Obelia; Meech, 1989, in Aglantha; Holman and Anderson, 1991, in Calliactis). We have presented a brief description of the transient calcium current from isolated SMNs of Polyorchis and have discussed its relevance to neuromuscular synaptic physiology (Spencer et al., 1989). Following the latter study, we have improved the composition of both electrode and bath solutions, allowing better identification of a very slowly inactivating component that was originally contaminated by residual outward current. We present an extensive description of the time courses, voltage dependencies, and ionic selectivities of the calcium currents, and include some pharmacological characterization of these currents. Possible mechanisms of ionic selectivity and inactivation, and the number of calcium channel populations present in these neurons are discussed.

\section{Materials and Methods}

Animals. Animals were collected in Bamfield Inlet (Vancouver Island, British Columbia) from the surface by dip netting, or at depth by scuba divers using plastic bags. The jellyfish were maintained in a recirculating, refrigerated $\left(10^{\circ} \mathrm{C}\right)$ aquarium containing a mixture of Rila Marine Mix and seawater from Bamfield Inlet, on a cycle of $12 \mathrm{hr}$ of light, $12 \mathrm{hr}$ of dark. The animals were fed newly hatched brine shrimp larvae once or twice a week.

Dissociation. The culture techniques are described more fully in Przysiezniak and Spencer (1989), but have been slightly modified and will be summarized here. The nerve rings were dissected from the bell margin as previously described and placed in artificial seawater (ASW; see below) in a borosilicate test tube for $5 \mathrm{~min}$. The solution was then replaced with $10 \%$ ASW for $5 \mathrm{~min}$ and with divalent cation-free ASW $\left(\mathrm{Ca}^{2+}\right.$ and $\mathrm{Mg}^{2+}$ replaced with choline and $1 \mathrm{~mm}$ EGTA) for $15 \mathrm{~min}$. Digestion was carried out in collagenase type I (Sigma), $1000 \mathrm{U} / \mathrm{ml}$ ASW, at room temperature $\left(20-25^{\circ} \mathrm{C}\right)$, for 3-7 hr depending on the integrity of the tissue (decreases with time since capture) observed during dissection. The enzyme solution was then replaced with an excess of ASW, with minimal disturbance to the tissue. The solution was pipetted off until the volume was appropriate for effective trituration and plating 
(usually $0.5 \mathrm{ml}$ for five dishcs). Up to 10 strokcs of trituration against the bottom of the test tube were given with a fire-polished Pasteur pipette. Three or four drops of the suspension were plated in the centers of Falcon 1008 culture dishes coated with dried homogenate of desalted, cleaned, bell mesoglea (Przysiezniak and Spencer, 1989). After being left to settle for $30 \mathrm{~min}$ to $4 \mathrm{hr}$ at room temperature, cultures were rinsed twice with ASW and incubated at $10^{\circ} \mathrm{C}$ until used. No nutrients were added to the cultures, which survived at least 1 week. Recordings were made on cells plated for $0-5 \mathrm{~d}$. Major features of the calcium and barium currents, namely time to peak, peak current, voltage dependence of activation, time course of inactivation, and voltage dependence of inactivation, did not change with the age of the culture.

Solutions. Artificial seawater contained (in $\mathrm{mm}$ ) $\mathrm{NaCl}, 378 ; \mathrm{CaCl}_{2}$, 9.5; $\mathrm{MgCl}_{2}, 29 ; \mathrm{Na}_{2} \mathrm{SO}_{4}, 5.7 ; \mathrm{KCl}, 13.4$; choline $\mathrm{Cl}$ (Cho-Cl), 42; HEPES buffer, $10 ; \mathrm{NaOH}, 5$. The antibiotic gentamycin sulfate was added at $50 \mathrm{mg} /$ liter. The $\mathrm{pH}$ of all solutions was adjusted to $7.5 \pm 0.05$. All culture and recording solutions were filtered through cellulose acetate or nylon membrane cartridges with $0.2 \mu \mathrm{m}$ pore size before use.

In early recordings, cesium was used to replace internal potassium and sodium while choline replaced external sodium ions. However, it was found that cesium ions carried a slow, outward current, possibly through potassium or calcium channels, which caused the apparent reversal of $I_{C a}$ at positive voltages (cf. Spencer et al., 1989) and when long depolarizations were given. In the experiments presented in this article, $N$-methyl-D-glucamine (NMG) replaced potassium and sodium inside as well as outside the cell, which eliminated the contaminating outward current.

All recordings were carried out with the following two solutions, unless otherwise specified. The bath solution for recording contained (in IIIM) $\mathrm{CaCl}_{2}, 10 ; \mathrm{MgCl}_{2}, 40 ; \mathrm{NMG}, 433$; HEPES, 10 ; and $\mathrm{HCl}, 421$. This composition was based on the results of analyses of ions in natural seawater and mesoglea using ion chromatography $\left(\mathrm{Cl}^{-}\right.$and $\left.\mathrm{SO}_{4}{ }^{2-}\right)$, atomic absorption spectroscopy $\left(\mathrm{K}^{+}\right)$, and inductively coupled plasma spectroscopy $\left(\mathrm{Na}^{+}, \mathrm{Mg}^{2+}, \mathrm{Ca}^{2+}\right)$. Magnesium and calcium in the bath were at concentrations close to their concentrations in seawater $(44.1 \mathrm{~mm}$ and $9.0 \mathrm{~mm}$, respectively). Barium replaced calcium mole for mole, where appropriate. Before recording from a culture, the medium was exchanged for recording bath solution by the slow addition of one bath volume followed by at least two complete bath exchanges.

The electrode solution contained (in mM) $\mathrm{CaCl}_{2}, 1$; EGTA, $11 ; \mathrm{MgCl}_{2}$, 2; NMG, 508; HEPES, 10; and $\mathrm{HCl}, 407$. The calcium concentration in this solution was estimated to be $\sim 1 \mathrm{nM}$, using a computer program (Stockbridge, 1987). To improve sealing, the electrode solution in some recent experiments was made hypotonic (90-98\%) by adding the appropriate amount of distilled water. Electrode solutions were allowed to dialyze into the cells, until current responses to voltage-clamp pulses were stable for more than $1 \mathrm{~min}$; this took 3-10 min, as estimated by maximal test responses elicited every minute.

Pharmacological agents. Cadmium was made up as a $100 \mathrm{~mm}$ solution in distilled water. Nifedipine (Sigma, N-7634) stock solution was made up to $10 \mathrm{~mm}$ in $5 \%$ dimethyl sulfoxide (DMSO) and $66.5 \%$ ethanol. Verapamil $\mathrm{HCl}$ (Sigma, V-4629) stock solution was $20 \mathrm{~mm}$ in $70 \%$ ethanol. Chemicals were diluted further in the recording bath solution and were either applied to the bath through a fine polyethylene tube to within $8 \mathrm{~mm}$ of the electrode tip or perfused into the bath $8-12 \mathrm{~mm}$ from the cell while suction was applied at the solution surface from the edge of the dish.

Electrodes and equipment. Electrodes were pulled on a Narishighe PP-83 puller, from non-heparinized hematocrit tubing (Fisher, thinwalled soda glass, cat. \#02-668-68). Before polishing, the electrode tips were dipped in a siliconizing agent, Sigmacote (Sigma), diluted to between $1 / 10$ and $1 / 20$ with $n$-heptane; this treatment significantly increased the rate and tightness of seal formation and greatly improved the quality of the phase-contrast optics when the electrode was in the bath. Electrodes were stored at room temperature, in a loosely covered jar for up to a few days. Day-old, siliconized electrodes seemed to attach better than did freshly siliconized electrodes, although both fresh and old electrodes were used in these experiments. The pipettes had an average resistance of $0.9 \mathrm{M} \Omega$ (range, $0.6-1.3 \mathrm{M} \Omega ; N=47$ ).

The cultures were viewed under phase contrast with a Nikon Diaphot inverted microscope. Electrodes were positioned with a "Huxley-Goodfellow" type micromanipulator (Campden Instruments, London, UK). Grounding was through a silver chloride-coated silver wire inserted into an agar bridge ( $4 \%$ agar in electrode solution). An L/M-EPC7 amplifier (List Medical, Darmstadt, Germany) was used for tight-seal, whole-cell voltage clamping. Stimulus control and data acquisition and processing were carried out with an IBM-PC computer, an XT clone, or a 386-SX clone, fitted with a Labmaster TL-1 interface, using pCLAMP 5.5 software (Axon Instruments interface and software).

Recordings. The swim motor neurons (SMNs) were identified by their characteristically large size (usually about $70 \mu \mathrm{m} \times 25 \mu \mathrm{m}$ ), compact shape, and clear cytoplasm (Przysiezniak and Spencer, 1989). Recordings were made at $20-22^{\circ} \mathrm{C}$. Long processes were absent or removed by cutting with a pipette tip. Seal resistances before access ranged between 0.5 and $5 \mathrm{G} \Omega$.

Leakage and capacitive current subtraction protocols were composed of four or five hyperpolarizing pulses one-fourth or one-fifth the size of the test pulse, respectively, and were applied from a holding potential of $-60 \mathrm{mV}$, before test pulses eliciting active responses were applied. Passive test responses to depolarizing or hyperpolarizing pulses of 40 $\mathrm{mV}$ amplitude lasting 5 or $10 \mathrm{msec}$ were recorded repeatedly during an experiment, usually before and after protocols eliciting active currents, to monitor series resistance $\left(R_{\text {ser }}\right)$ and leakage resistance $\left(R_{\text {leak }}\right)$. Test pulses were applied from a holding potential of $-80 \mathrm{mV}$ if depolarizing and from $-40 \mathrm{mV}$ if hyperpolarizing. Passive responses were low-pass filtered at $10 \mathrm{kHz}$, while active responses were filtered at $3 \mathrm{kHz}$ before acquisition, using a three-pole Bessel filter.

$R_{\text {tcak }}$ was calculated from the current at the end of the passive responses. $R_{\text {ser }}$ was estimated from the amplitude of the capacitive transient, obtained by back-extrapolation of a single-exponential fit to the beginning of the passive test pulse. The voltage crror caused by active currents flowing through $R_{\mathrm{scr}}$ was calculated as follows: leakage current was calculated from $R_{\text {leak }}$ and the amplitude of the command pulse and was added to the active current amplitude; the voltage error was obtained as the product of $R_{\text {ser }}$ by this "reconstituted" current. No $R_{\text {ser }}$ compensation was used since active currents were small. In addition, the rising phase of active currents was masked by an initial, transient, outward current and could not have been resolved further by $R_{\mathrm{ser}}$ compensation.

Data analysis. Data for all experiments were selected on the basis of the following criteria. (1) The neuron must be clearly identified as a "swim motor neuron" by its large size, compact shape, and clear cytoplasm (Przysiezniak and Spencer, 1989). While characteristic plateau action potentials were produced by these cells in normal ionic conditions (Spencer, 1981; Przysiezniak and Spencer, 1989), no spikes were generated in calcium current recording conditions; thus, spike shape could not be used for cell identification. (2) Leakage resistance must be larger than or equal to $0.5 \mathrm{G} \Omega$. (3) Series resistance must not exceed $10 \mathrm{M} \Omega$. (4) Active currents must show no sign of major instability such as the large, random fluctuations caused by seal disruption.

Unless specified, data for calcium and barium currents were collected from different cells, in static conditions, that is, without solution changes, because superfusions tended to disrupt recordings. Comparisons between calcium and barium currents are thus between populations of cells.

All traces were digitally filtered at $1 \mathrm{kHz}$ (Gaussian filter) before measurements were taken. Peak currents were measured using the automatic peak detection function in the Clampan section of the pCLAMP software. Late currents measured isochronally were taken slightly before the end of the pulse (e.g., at $78.2 \mathrm{msec}$ on an $80 \mathrm{msec}$ pulse) to avoid capacitive transients spread out by digital filtering.

We attempled to normalize absolute current amplitudes to current densities, using capacitance as an estimate of cell surface. Cell capacitance was obtained by calculation from $R_{\mathrm{ser}}$ and $\tau$ values measured from the passive test responses, and by integration of the capacitive transients. However, the variability in the data did not seem to be diminished by this approach, suggesting that capacitance is not a reliable indicator of cell surface, or that channel number is independent of cell surface area. Consequently, we have not used this type of normalization.

Statistical significance was determined as a probability of 0.05 or less, obtained from a two-tailed Student's $t$ test (Sokal and Rohlf, 1981).

Equations and curve fitting. Exponentials were fitted to current traces using the Clampfit section of the pCLAMP 5.5 softwarc (Axon Instruments). Exponentials in the experiments on recovery from inactivation were fitted with a C-language (Turbo-C, version 2, Borland International) program using a least-squares procedure.

Initial transient current activation curves were fitted with a modified Boltzmann distribution:

$$
I_{\text {init }}=I_{\min }+\left(I_{\max }-I_{\min }\right) /\left\{1+\exp \left[\left(V_{a}-V\right) / K_{a}\right]\right\},
$$


where $I_{\min }$ is an offset component, $I_{\max }$ is the current at saturation, $V_{b}$ is the voltage at half-activation, and $K_{a}$ is the steepness factor. This and other equations were fitted by iterating parameters to the nearest singledecimal value $(0.1 \mathrm{mV}$ or $0.1 \mathrm{pA})$ using a least-squares procedure adapted to a spreadsheet (MICROSOFT EXCEL, version 2.2, Microsoft Corporation).

Other equations fitted are described in the appropriate table notes.

\section{Results}

The following evidence will show that the most prominent calcium current in SMNs of Polyorchis, the high-voltage-activated (HVA) current, exhibits a transient, ion-selective component (HVA-t) and a sustained, nonselcetive component (HVA-s). These will be distinguished and described in sections on time course, voltage dependence of activation, and steady-state inactivation. A third, "very-high-voltage-activated" (VHVA) current exhibits a more positive $I-V$ relationship and a slower onset, and will be distinguished from the HVA currents in the section on voltage dependence of activation. First, however, we describe the passive cell properties, and we distinguish $I_{\mathrm{Ca}}$ from sodium currents and a possible gating current.

\section{Passive properties}

The passive membrane properties of SMNs were measured from responses to $\pm 40 \mathrm{mV}$ pulses applied from $-80 \mathrm{mV}$ (if depolarizing) or $-40 \mathrm{mV}$ (if hyperpolarizing). Leakage resistances $\left(R_{\text {leak }}\right)$ had a mean of $1.2 \mathrm{G} \Omega$ (range, $0.5-3.7 \mathrm{G} \Omega ; N=123$ measurements). The series resistance $\left(R_{\mathrm{ser}}\right)$ averaged $3.8 \mathrm{M} \Omega$, ranging from 1.4 to $9.1 \mathrm{M} \Omega$. Single-exponential fits to the transients decayed $e$-fold in $121 \mu \mathrm{sec}$ (range, 36-246 $\mu \mathrm{sec}$ ), indicating a cell capacitance around $30 \mathrm{pF}$. As calculated from these fits, voltage-clamp pulses reached $95 \%$ of the command step after an average of $362 \mu \mathrm{sec}$ (range, 108-737 $\mu \mathrm{sec}$ ). In data collected with a single electrode, double exponentials fitted the capacitive transients slightly better than did single exponentials, yielding a rapidly decaying component $(\tau=88 \mu \mathrm{sec})$ and a slower component $(\tau=542 \mu \mathrm{sec}$ ), which represented about $1.8 \%$ (range, $0.2-9.1 \%$ ) of the total transient amplitude, indicating the presence of an electrically remote part of the cell membrane even in cells that were almost spherical. The average voltage error due to active currents flowing through $R_{\text {ser }}$ was calculated to be $-0.4 \mathrm{mV}$ at maximal calcium current (range, -1.5 to +0.3 $\mathrm{mV})$.

\section{Distinguishing $I_{\mathrm{Ca}}$ from other currents}

In conditions where the only permeant ion in the bath was calcium ( $9.5 \mathrm{~mm}$ ), an inward, inactivating current was observed in response to $50-\mathrm{msec}$-long depolarizing pulses to $+20 \mathrm{mV}$ (Fig. 1) from a holding potential of $-40 \mathrm{mV}$. This current was eliminated by the replacement of external calcium with cobalt $(N=9)$. It was not carried by magnesium, since a 10 -fold reduction of $[\mathrm{Mg}]_{o}$ (lo $4 \mathrm{~mm}$ ) did not change the amplitude of the current ( $N=3$; data not shown). $I_{\mathrm{Ca}}$ showed very little "rundown" after more than $60 \mathrm{~min}$. When the cell was suddenly released from voltage clamp to current clamp, the membrane potential rose slowly, then rapidly to a resting level around +15 mV.

Calcium current is known to flow through sodium channels in the squid giant axon when the bath solution contains no sodium and a large concentration of calcium (Meves and Vogel, 1973). To show that channels specific for calcium, and not sodium, mediated the calcium current, recordings were made in

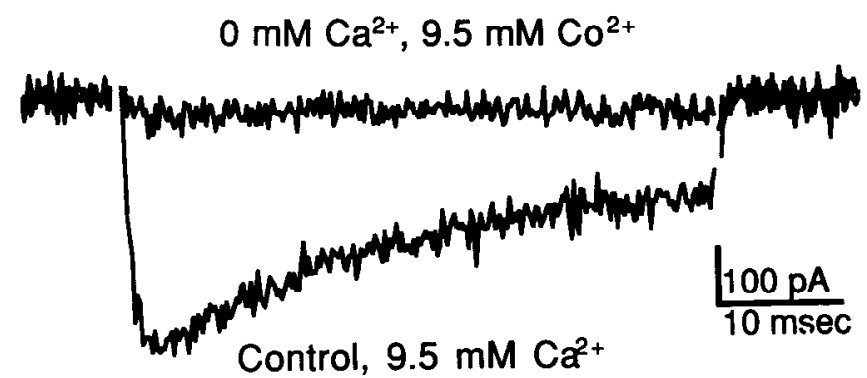

Figure 1. Calcium current from an identified SMN of the jellyfish Polyorchis penicillatus. Current responses from one cell elicited by 50 msec voltage-clamp pulses, from a holding potential $\left(V_{h}\right)$ of $-40 \mathrm{mV}$ to a command potential $\left(V_{c}\right)$ of $+20 \mathrm{mV}$, in normal conditions and with external $\mathrm{Ca}^{2+}$ replaced with $\mathrm{Co}^{2+}$. Sampling interval was $100 \mu \mathrm{sec}$. Subtraction carried out with a $-p / 5$ protocol from $-40 \mathrm{mV}$. Bath solution contained (in mM) $\mathrm{MgSO}_{4}, 5.7 ; \mathrm{MgCl}_{2}, 23.3 ; \mathrm{CaCl}_{2}$ or $\mathrm{CoCl}_{2}$, 9.5; $\mathrm{KCl}, 7.8$; $\mathrm{Cho}-\mathrm{Cl}, 437$; HEPES, 10 ; and $\mathrm{KOH}, 5.6$. Electrode solutions contained (in $\mathrm{mM}$ ) $\mathrm{CsCl}, 109 ; \mathrm{MgCl}_{2}, 2 ; \mathrm{CaCl}_{2}, 1$; HEPES, 10 ; EGTA, 11; dextrose, 536; tetraethylammonium chloride, 100; and $\mathrm{CsOH}$, 31.

conditions where both $I_{\mathrm{Na}}$ and $I_{\mathrm{Ca}}$ could occur simultaneously while no other permeant ion was present. Under these conditions, two currents with distinctly different time courses could be recorded. Figure 2 shows that a net inward current was observed in saline containing $100 \mathrm{mM} \mathrm{Na}^{+}$and $10 \mathrm{~mm} \mathrm{Ca}^{2+}$, and with an internal solution containing $50 \mathrm{mM} \mathrm{Na}{ }^{+}$and low calcium. When the sodium gradient was reversed by a brief superfusion with $\mathrm{Na}^{+}$-free saline, a rapid, transient outward current carried by sodium and a slower, inactivating, inward current carried by calcium occurred simultaneously. Further superfusion increased the outward $I_{\mathrm{Na}}$, which almost swamped $I_{\mathrm{Ca}}$.

In separate recordings of $I_{\mathrm{Na}}$ and $I_{\mathrm{Ca}}$, cadmium specifically blocked the calcium current (see Fig. 9A) but did not affect the sodium current substantially (J. Przysiezniak and A. N. Spencer, unpublished observations), once more indicating that distinct channel populations mediated these two currents.

The selectivity of the calcium channels for divalent cations, such as calcium or barium, may not be absolute. For example, in the absence of calcium or barium (replaced with cobalt) and in the presence of sodium, the SMNs were seen to generate plateau action potentials (data not shown), which are typically produced by calcium currents (e.g., see Fig. 9B). This suggests the calcium channels in SMNs pass sodium ions in the absence of divalent cations, a common occurrence in other preparations (e.g., Hess and Tsien, 1984; Lux et al., 1990).

When either $\mathrm{Ca}^{2+}$ or $\mathrm{Ba}^{2+}$ was the only permeant ion inside and outside the cell, a transient, outward current usually preceded the inward current (Fig. 3A). This outward current was not a capacitive artifact, because $R_{\text {ser }}$ compensation did not remove it. This current was not visible in the experiment shown in Figure $2 A$ because the rapid, outward, sodium current masked it. The transient, outward current appeared to be larger in barium than in calcium (Fig. $3 A$; see below), probably because the inward current was smaller in barium and masked less of the transient current. In response to graded depolarizations, the transient current measured at $600 \mu \mathrm{sec}$ from the beginning of averaged traces (nine cells in each ion) showed a sigmoid voltage dependence. This transient outward current may have reflected the movement of channel-gating charges in sodium, potassium, or calcium channels. 

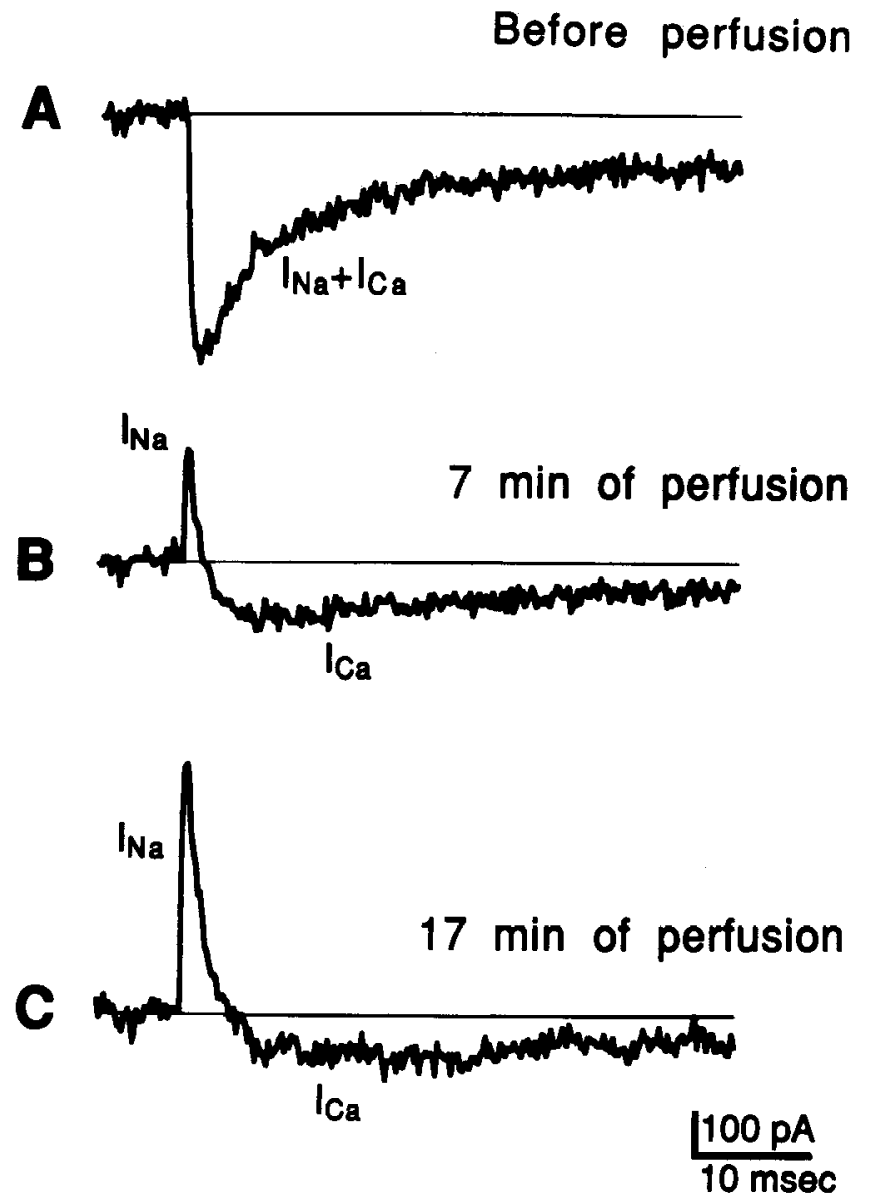

Figure 2: Simultaneous recordings of sodium and calcium currents from one cell in conditions where both currents are of similar amplitude, showing they are carried through different channel populations. In control conditions, the bath contained $10 \mathrm{mM} \mathrm{Ca}^{2+}, 40 \mathrm{mM} \mathrm{Mg}^{2+}, 100 \mathrm{~mm}$ $\mathrm{Na}^{+}$, and no $\mathrm{K}^{+}$(NMG substitution), while the electrode contained $\sim 1$ $\mathrm{nM} \mathrm{Ca}{ }^{2+}, 2 \mathrm{~mm} \mathrm{Mg}{ }^{2+}, 50 \mathrm{mM} \mathrm{Na}^{+}$, and no $\mathrm{K}^{+}$. The bath was superfused four times for short periods $(30-120 \mathrm{sec})$ with sodium-free solution, alternating with equilibration periods of 1-2 min. Traces were taken just before the first superfusion $(A)$, after the second superfusion $(B)$, and after the fourth (last) supcrfusion $(C)$. Sampling interval was 200 $\mu$ sec. Voltage pulses were applied from $V_{h}-80 \mathrm{mV}$ to $V_{c}+10 \mathrm{mV}$ for $A-C$. Subtraction protocol was $+p / 4$ from $-80 \mathrm{mV}$. Data points during capacitive artifacts were set to zero, for clarity. The flat line is zero current in this and the following figures.

\section{Time course of maximal responses}

Most of the experiments described in this and the following sections were carried out on both calcium and barium currents, with external $\mathrm{Ca}^{2+}$ or $\mathrm{Ba}^{2+}$ at a concentration of $10 \mathrm{~mm}$. Usually, only one of the two ionic species was used in a given cell so that calcium and barium current data were collected from sets of different cells. All data are expressed as mean \pm SEM.

In all cells with SMN morphology, maximal, rapidly activating divalent cation currents could be elicited by voltageclamp commands $\left(V_{c}\right)$ to $+10 \mathrm{mV}$ from a holding potential $\left(V_{h}\right)$ of $-80 \mathrm{mV}$. The early activation phase of $I_{\mathrm{Ca}}$ and $I_{\mathrm{Ba}}$ was contaminated by capacitive transients, which saturated the analogto-digital converter for the first $\sim 0.5 \mathrm{msec}$, and by the transient, initial, outward current (see above section), which occupied the next $\sim 0.5 \mathrm{msec}$. Consequently, exponential fitting to the rising phase was not done and time to peak $\left(T_{\text {peak }}\right)$ was used to estimate activation rate.
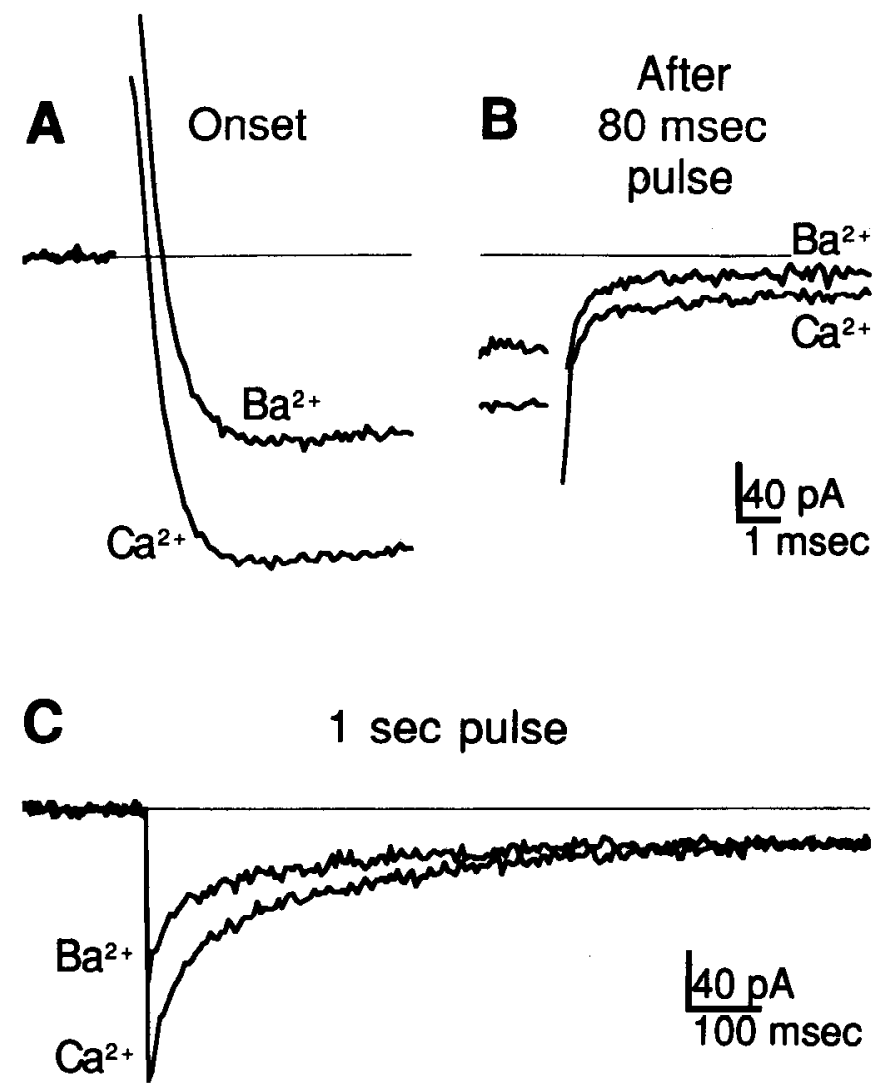

Figure 3. Superimposed, maximal $I_{\mathrm{Ca}}$ and $I_{\mathrm{Ba}}$ responses elicited by voltage-clamp stimuli from $V_{n}-80 \mathrm{mV}$ to $V_{c}+10 \mathrm{mV}$. $A$ and $B$, Currents at beginning and at end of responses to $80 \mathrm{msec}$ pulses, respectively, averaged for nine cells in each ionic condition. Sampling interval was $100 \mu \mathrm{sec}$. The scale is the same for $A$ and $B$. The initial, outward, transient currents in $A$ were truncated for the first $0.5 \mathrm{msec}$, approximately, to remove the unsubtracted capacitive transient. $C$, Currents elicited by 1 sec pulses, averaged for six cells in $\mathrm{Ca}^{2+}$ and seven cells in $\mathrm{Ba}^{2+}$, showing rapidly and slowly inactivating current components. Sampling was every $5 \mathrm{msec}$. Solutions are described in Materials and Methods.

Table 1 summarizes and compares the different features of maximal calcium and barium current responses. Both $I_{\mathrm{Ca}}$ and $I_{\mathrm{Ba}}$ activated rapidly at similar rates, each reaching a peak in about $4 \mathrm{msec}$, at which point $I_{\mathrm{Ba}}$ was $40 \%$ smaller than $I_{\mathrm{Ca}}$ (Fig. $3 A$, Table 1). The inactivation phase of the responses during $400 \mathrm{msec}$ pulses to $+10 \mathrm{mV}$ followed a double-exponential time course that reached a non-zero steady state. The back-extrapolated amplitudes of both rapidly and slowly inactivating components were significantly larger in calcium than barium (Table 1). $I_{\mathrm{Ba}}$ and $I_{\mathrm{Ca}}$ exhibited only slight, statistically insignificant differences between the time constants fitted. The amplitude of $I_{\mathrm{Ba}}$ was significantly smaller than that of $I_{\mathrm{Ca}}$ for the first several hundred milliseconds, while the amplitudes of the currents carried by both ionic species reached an identical, sustained level at the end of 1-sec-long pulses (Fig. 3C, Table 1). These results indicate the presence of a transient, selective current with complex inactivation, and a sustained, nonselective current.

Tail currents were visible upon rcpolarization to $-80 \mathrm{mV}$ (Fig. $3 B$ ), in calcium and barium. A large, rapid $(\sim 200 \mathrm{pA} ; \tau$ $\sim$ 150-290 $\mu \mathrm{sec})$, exponential component occurred within the voltage-clamp transition time ( $\sim 360 \mu \mathrm{sec}$; see above), and was too rapid to measure accurately. A smaller, slower relaxation 
Table 1. Features of maximal calcium and barium currents in swim motor neurons of Polyorchis penicillatus

\begin{tabular}{|c|c|c|c|}
\hline & $I_{\mathrm{Ca}}$ & $I_{\mathrm{Ba}}$ & $P$ \\
\hline Time to peak (msec) ${ }^{a}$ & $4.0 \pm 0.3(9 / 7)$ & $4.3 \pm 0.2(9 / 5)$ & NS \\
\hline Peak current $(\mathrm{pA})^{a}$ & $-217 \pm 23(9 / 7)$ & $-131 \pm 14(9 / 5)$ & $0.001-0.01$ \\
\hline Amplitude of fast decay $(\mathrm{pA})^{b}$ & $-88.4 \pm 7.9(10 / 3)$ & $-61.1 \pm 5.1(14 / 5)$ & $0.001-0.01$ \\
\hline$\tau$ of fast decay $(\mathrm{msec})^{b}$ & $25.6 \pm 2.8(10 / 3)$ & $20.9 \pm 1.6(14 / 5)$ & NS \\
\hline Amplitude of slow decay $(\mathrm{pA})^{b}$ & $-99.5 \pm 9.0(10 / 3)$ & $-50.7 \pm 4.5(14 / 5)$ & $<0.001$ \\
\hline$\tau$ of slow decay $(\mathrm{msec})^{b}$ & $187 \pm 21(10 / 3)$ & $244 \pm 60(14 / 5)$ & NS \\
\hline Current at $1 \sec (\mathrm{pA})^{c}$ & $-24.5 \pm 5.0(6 / 3)$ & $-29.2 \pm 7.2(7 / 4)$ & NS \\
\hline Sustained tail current $6.2 \mathrm{msec}$ after $80 \mathrm{msec}$ pulse $(\mathrm{pA})^{a}$ & $-29.0 \pm 3.5(9 / 7)$ & $-12.5 \pm 1.5(9 / 5)$ & $<0.001$ \\
\hline
\end{tabular}

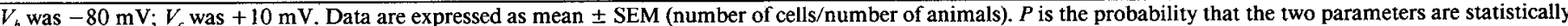
indistinguishable, from a two-tailed Student's $t$ test; only significant probabilities $(\leq 0.05)$ are indicated. NS, not significant.

a Measured from responses to $80 \mathrm{msec}$ pulses.

bitted to responses to $400 \mathrm{msec}$ pulses.

c Measured from responses to $1 \mathrm{sec}$ prepulses of inactivation protocols.

component ( $\sim 20 \mathrm{pA} ; \tau \sim 2 \mathrm{msec}$ ) and a small, sustained tail current could be seen upon repolarization to $-80 \mathrm{mV}$ from test pulses eliciting $I_{\mathrm{Ca}}$ or $I_{\mathrm{Ba}}$. The sustained $I_{\mathrm{Ca}}$ tail current was absent after return to a holding potential of $-40 \mathrm{mV}$, suggesting it was not a chloride current ( $E_{\mathrm{Cl}} \sim 0 \mathrm{mV}$, in these conditions). The sustained tail current was larger in calcium than barium, like the selective, transient current seen above. It was not an artifact of leakage subtraction because it was also observed without subtraction. Neither was it an artifact of bad space clamping, because it was observed in multiple-channel patches (preliminary data), which should have been well clamped. It likely represented current through ion-selective calcium channels.

\section{Voltage dependence of activation of divalent cation currents}

\section{Current-voltage relationships}

The transient and sustained currents differed little in their current-voltage $(I-V)$ relationships (Fig. $4 A, B$ ). The peak current on $80 \mathrm{msec}$ pulses and the current at the end of 1 sec pulses first activated around $-30 \mathrm{mV}$, rose sigmoidally with voltage, and reached a maximum around $+10 \mathrm{mV}$. Because of their voltage range of activation and their time courses, these currents will be referred to as the HVA-t (HVA, transient) current and the HVA-s (HVA, sustained) current, respectively.

The maxima of $I_{\mathrm{Ca}}$ and $I_{\mathrm{Ba}}$ occurred at the same voltage $(+10$ $\mathrm{mV}$ ), suggesting barium and calcium exerted the same effect on the membrane surface potential. It is unlikely that surface charges were altogether absent because a 10 -fold decrease of external magnesium concentration caused a $-10 \mathrm{mV}$ shift of the voltagc of maximal $I_{\mathrm{Ca}}(N=3$; data not shown). The HVA-t component was significantly larger in $\mathrm{Ca}^{2+}$ than $\mathrm{Ba}^{2+}$ from $-10 \mathrm{mV}$ to +60 $\mathrm{mV}$ (Fig. $4 A$ ), while no such selectivity was apparent for the HVA-s current (Fig. 4B).

Current responses to commands ranging up to $+70 \mathrm{mV}$ behaved in a manner that suggested the presence of another current, which seemed to activate at higher voltages but with a slower time course than did the HVA components. This VHVA (very-high-voltage-activated) current was most evident using averaged barium current responses. Figure $5 A$ shows $I_{\mathrm{Ca}}$ and $I_{\mathrm{Ba}}$ responses to an incrementing series of $80 \mathrm{msec}$ depolarizations applied from a $V_{h}$ of $-80 \mathrm{mV}$. At voltages beyond $+40 \mathrm{mV}$, the population-averaged $I_{\mathrm{Ca}}$ activated fairly rapidly and inactivated partially during the pulse, while $I_{\mathrm{Ba}}$ arose slowly $(\tau \sim 10$ msec) and showed little inactivation for the duration of the stimulus. Apparently, at very high voltages, the HVA-t current was small when barium was the charge carrier, but the more slowly activating, VHVA component was carried equally well by barium or by calcium.

Although both the VHVA and the HVA-s currents appear to be nonselective, they are likely not mediated by the same channels because their voltage dependencies are clearly different. A plot of $I_{\mathrm{Ba}}$ at $78 \mathrm{msec}$ versus voltage shows a distinct shoulder at about $+50 \mathrm{mV}$ (Fig. 5B). This shoulder was not an artifact of subtracting nonlinear leakage responses from the test-pulse responses because a shoulder could be observed at very positive test-pulse voltages when the unsubtracted, late $I_{\mathrm{Ba}}$ was plotted (data not shown). Seven of the nine cclls exhibited a secondary increase in barium current between $+30 \mathrm{mV}$ and $+60 \mathrm{mV}$.

The sustained tail current showed a nonsaturating $I-V$ relationship (data not shown), reflecting contamination by an additional, decaying tail current apparent after large depolarizations (Fig. $5 A$, traces at $+60,+70 \mathrm{mV}$ ). This is likely associated with the VHVA current.

\section{Simulated I-V curves and activation curves}

Steady-state activation of the HVA-t current was determined assuming that the amplitude of the peak current represented the steady-state current that would have been measured in the absence of inactivation. Single-exponential fits to the inactivation phase of $80 \mathrm{msec}$ responses were back-extrapolated to the voltage transition, and these initial current amplitudes, equivalent to steady-state $I_{\mathrm{Ca}}$ or $I_{\mathrm{Ba}}$, were found not to be significantly different from peak amplitudes.

Simulated curves (equations in Table 2 notes) were fitted to the $I-V$ data in Figure $4 A$. Curves fitted assuming a single current component (Fig. $4 A$, broken curves) corresponded well with the HVA-t maximum but were smaller than the data at very positive voltages. This difference was statistically significant from +50 $\mathrm{mV}$ to $+70 \mathrm{mV}$ for $I_{\mathrm{Ca}}$, and at $+50 \mathrm{mV}$ for $I_{\mathrm{Ba}}$, and probably reflected the appearance of the VHVA component at those voltages. Curves fitted assuming two components (Fig. $4 \mathrm{~A}$, solid curves) showed no statistical difference from the data at any voltage, for both ions.

Table 2 shows the average parameters used to fit simulated $I-V$ curves to data from individual cells. The only parameter that showed any significant difference between ionic conditions was the maximal permeability of the HVA- $t$ component, which was smaller for $I_{\mathrm{Ba}}$ than for $I_{\mathrm{Ca}}$. The voltages at half-activation 

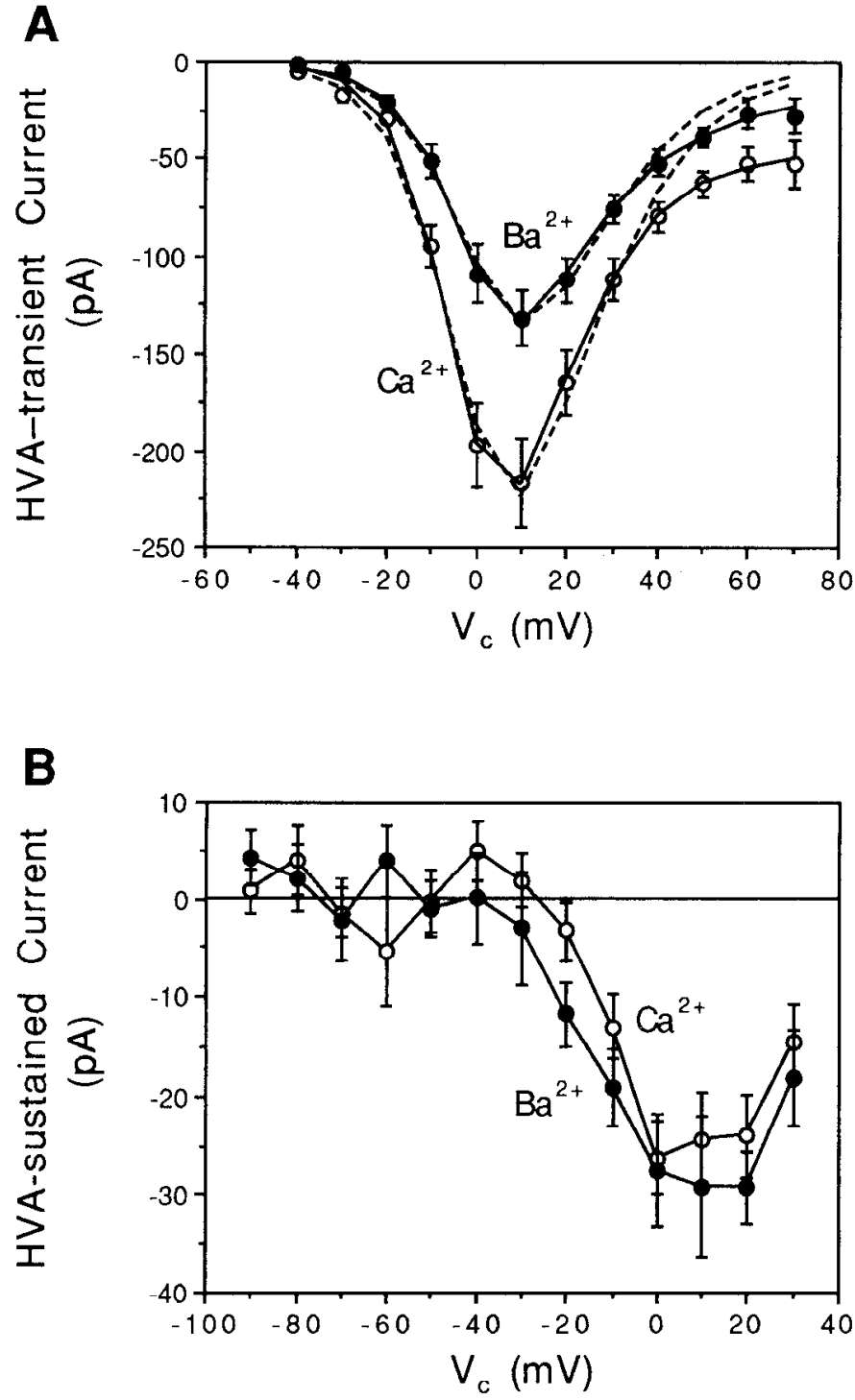

Figure 4. Current-voltage relationships of HVA-t $(A)$ and HVA-s $(B)$ currents recorded in calcium and barium. The HVA-t was carried by calcium more easily than by barium, over a wide voltage range, while the sustained component was indifferent to the ionic species. Data are plotted as mean \pm SEM in this and the following graphs. $A$, Transient $I_{\mathrm{Ca}}$ and $I_{\mathrm{Ba}}$ versus voltage. An automatic peak-detection function was used to measure the largest current between $1.2 \mathrm{msec}$ and $18.7 \mathrm{msec}$ in recordings from nine cells in each ionic condition. The broken curves are mathematical fits of Boltzmann and constant-field equations, calculated assuming only one current component, while the solid curves were calculated assuming two components. The equations are given in the Table 2 notes. At very positive voltages, HVA-t is contaminated by the VHVA current. $B$, Sustained current. Measurements were taken near the end of $1 \mathrm{sec}$ "steady-state inactivation" prepulses (cf. Fig. 8). Means are from six cells in calcium, seven in barium.

( $\left.V_{a, \mathrm{HV}}\right)$ and the slope factors $\left(K_{a, \mathrm{HV}}\right)$ of the HVA-t current did not appear significantly sensitive to ionic species. The parameters fitted to the VHVA current data showed relatively larger standard errors than did the HVA-t parameters, indicating that this current did not behave consistently in different cells.

The sigmoid, voltage-dependent activation of HVA-t was calculated as described in the Figure 6 caption. The resulting activation curves were averaged and plotted in that figure. The curves for normalized permeabilities $P_{\mathrm{Ca}}$ and $P_{\mathrm{Ba}}$ showed sig- nificant differences only at $-30 \mathrm{mV}$ and $-10 \mathrm{mV}$ (standard errors were very small). The HVA-t permeability first activated just above $-30 \mathrm{mV}$, reached half-activation just above $0 \mathrm{mV}$, and saturated around $+40 \mathrm{mV}$. The activation curve of the VHVA component that was extracted from the averaged data first activated around $+20 \mathrm{mV}$ and saturated beyond the voltage range studied (not shown). Similar results were obtained regarding VHVA activation when measurements were taken at the end of $80 \mathrm{msec} I_{\mathrm{Ba}}$ responses, where VHVA was most prominent (Fig. 5B).

\section{Time to peak}

Time-to-peak current (Fig. 7) followed a U-shaped function of voltage, reflecting the appearance of the slowly rising, VHVA current in addition to the HVA-l current. If a single population of HVA channels was present, $T_{\text {peak }}$ would decline as the channels activate, without increasing again, assuming these channels exhibit classical activation kinetics.

Times to peak were statistically indistinguishable between $I_{\mathrm{Ca}}$ and $I_{\mathrm{Ba}}$ at all voltages but $-10 \mathrm{mV}$, although $T_{\text {peak }}$ was consistently longer for $I_{\mathrm{Ba}}$ than $I_{\mathrm{Ca}}$, at voltages where the VHVA current did not contaminate the HVA-t responses $(-10 \mathrm{mV}$ to +20 $\mathrm{mV}$ ). Two repeated "autopeak" measurements (cf. Fig. 4 caption) using search regions of varying sizes gave differences in the same direction, although in no case was there statistical significance of the average difference calculated across four voltages. The speed of voltage clamping did not appear to depend on ionic conditions, because the time constants of passive, capacitive current decay did not differ significantly between the $I_{\mathrm{Ca}}$ and $I_{\mathrm{Ba}}$ conditions.

\section{Steady-state inactivation of HVA currents}

The availability of peak $I_{\mathrm{Ca}}$ or $I_{\mathrm{Ba}}$ was measured immediately after $1 \mathrm{sec}$ prepulses during which inactivation had reached a steady state. Prepulse/test pulse pairs were applied every $10 \mathrm{sec}$. Both ascending and descending voltage series gave similar results, indicating there was little cumulative inactivation at this stimulation rate. Only data from the ascending series were used.

The steady-state inactivation data (Fig. 8A) suggested the presence of distinct components of the calcium current, one showing selectivity for calcium over barium and inactivation with depolarizing prepulses, and another showing no selectivity and incomplete inactivation at the positive prepulses applied. Peak $I_{\mathrm{Ca}}$ and $I_{\mathrm{Ba}}$ differed in amplitude following negative prepulses. The difference was significant from $-90 \mathrm{mV}$ to -20 $\mathrm{mV}$. Up to $-50 \mathrm{mV}, I_{\mathrm{Ca}}$ seemed to show a slight, progressive decrease, while $I_{\mathrm{Ba}}$ did not appear to change. Above $-50 \mathrm{mV}$, increasingly positive prepulses inactivated the peak current. Following prepulses above $0 \mathrm{mV}$, a significant current $(\sim-31 \mathrm{pA}$ $p<0.001$ for $I_{\mathrm{Ca}}$ and $I_{\mathrm{Ba}}$ being different from zero) persisted that had the same amplitude in calcium and barium. These data mirror the results of Figure $3 C$, which shows the prepulse responses exhibiting inactivating (HVA-t) and sustained (HVAs) components with different ionic selectivities. In addition, Figure $8 A$ shows that the two components are further distinguished by their different voltage dependencies of inactivation. The slight recovery from inactivation at positive voltages was not significant, even after prepulses to $+50 \mathrm{mV}$ (data not shown).

Data from Figure $8 \mathrm{~A}$ were fitted with a modified Boltzmann distribution. Table 3 gives the equation fitted and the fitting parameters for steady-state calcium and barium current inactivation, which were averaged from fits to individual data sets. 
A

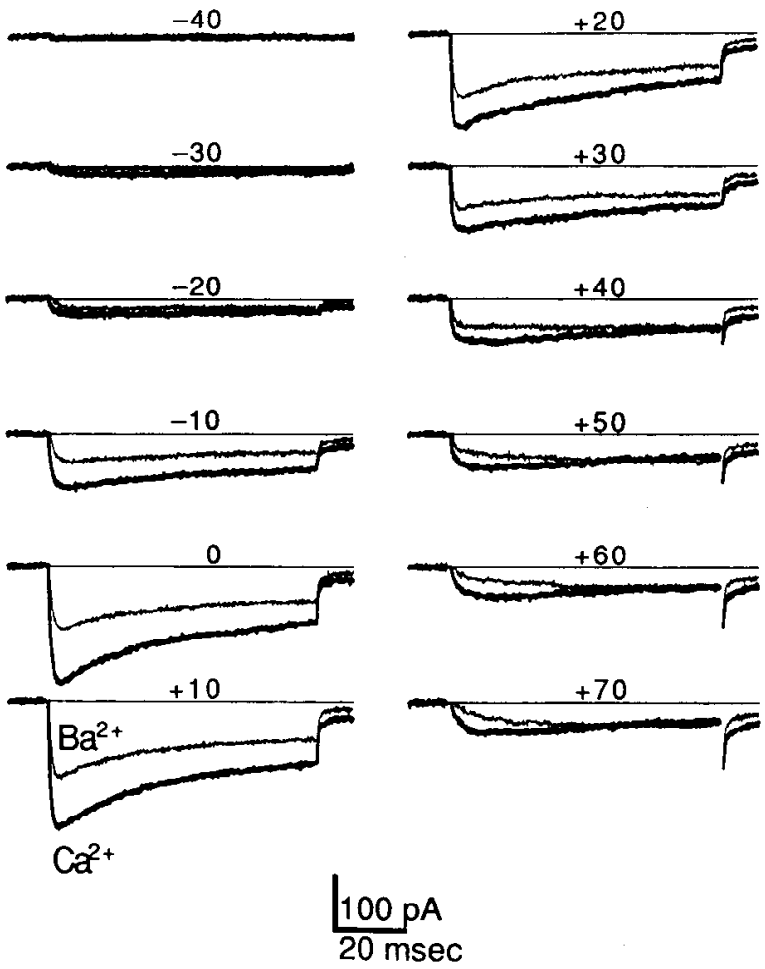

B

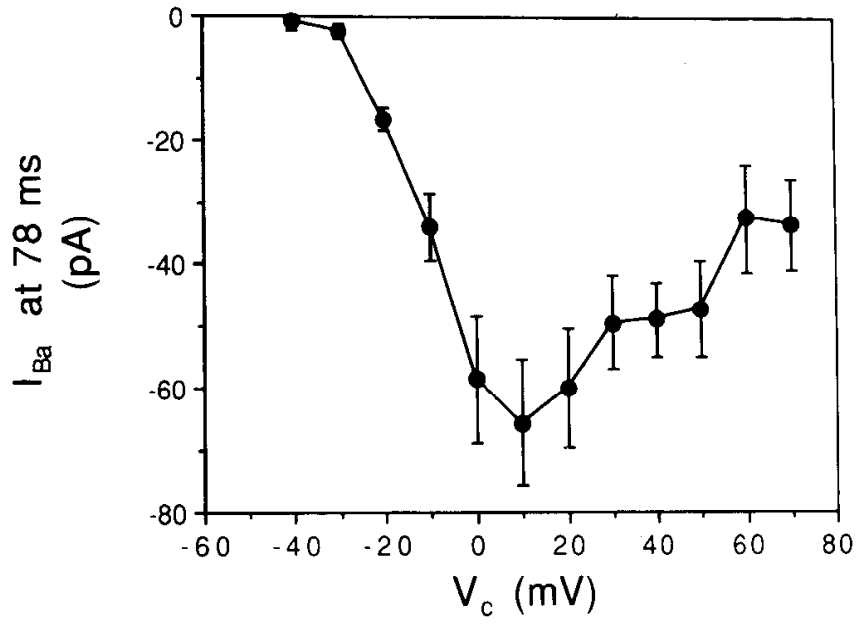

Figure 5. Divalent cation current responses to depolarizing voltage pulses and the VHVA current. $A$, Superimposed $I_{\mathrm{Ca}}\left(\right.$ thick traces) and $I_{\mathrm{Ba}}($ thin traces) responses to graded, $80 \mathrm{msec}$ voltage-clamp pulses, averaged for nine cells in each condition. The stimulating voltages are indicated above the traces (in $\mathrm{mV}$ ). The sampling interval was $100 \mu \mathrm{sec}$. The currents at the voltage transitions were removed for clarity. The responses are sclective for calcium over barium for most of the voltage range. At very positive voltages $(\sim+50 \mathrm{mV})$, the slowly arising, nonselective VHVA current appears. $B, I_{\mathrm{Ba}}$ measured isochronally at $78 \mathrm{msec}$, as a function of stimulating voltage, showing a prominent shoulder around $+50 \mathrm{mV}$, which indicates the presence of the VHVA current.

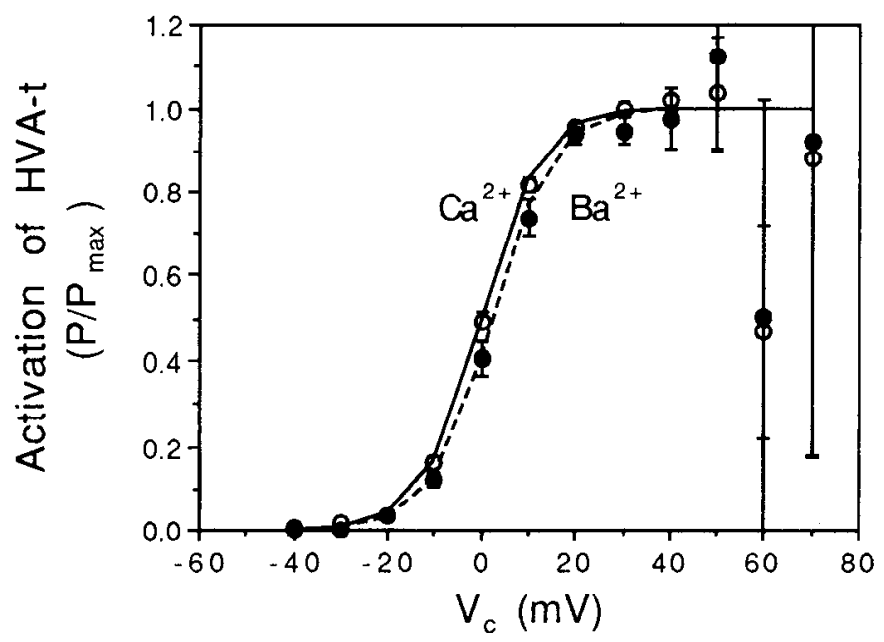

Figure 6. Activation of HVA-t with voltage in calcium and barium, expressed as the ratio $P / P_{\max }$ calculated from the data in Figure $4 A$ and from simulated $I-V$ curves fitted to these data. Points $\left(\mathrm{Ca}^{2+}\right.$, open circles; $\mathrm{Ba}^{2+}$, solid circles) are mean ratios. Solid $\left(\mathrm{Ca}^{2+}\right)$ and broken $\left(\mathrm{Ba}^{21}\right)$ curves are Boltzmann distributions with parameters from fits to the average $I-V$ data, as shown in Table 2 . To obtain activation data for the HVA current, total divalent cation permeability was calculated at each voltage using the GHK equation (Table 2), the expected permeability $P_{D, \mathrm{VHV}}$ was calculated from the Boltzmann equation, and the latter was subtracted from the former to obtain $P_{D, \mathrm{HV}}$. This was normalized to $\mathrm{P}_{\mathrm{max}, \mathrm{HV}}$ and plotted.
Normalized, steady-state inactivation curves for the transient $I_{\mathrm{Ca}}$ and $I_{\mathrm{Ba}}$ are presented in Figure $8 B$. The voltage dependencies of inactivation were identical in calcium and barium.

Preliminary experiments using barium currents to measure the time course of recovery from inactivation of the peak, HVA- $t$ component gave an average time constant of $50 \mathrm{msec}$ at -80 $\mathrm{mV}$.

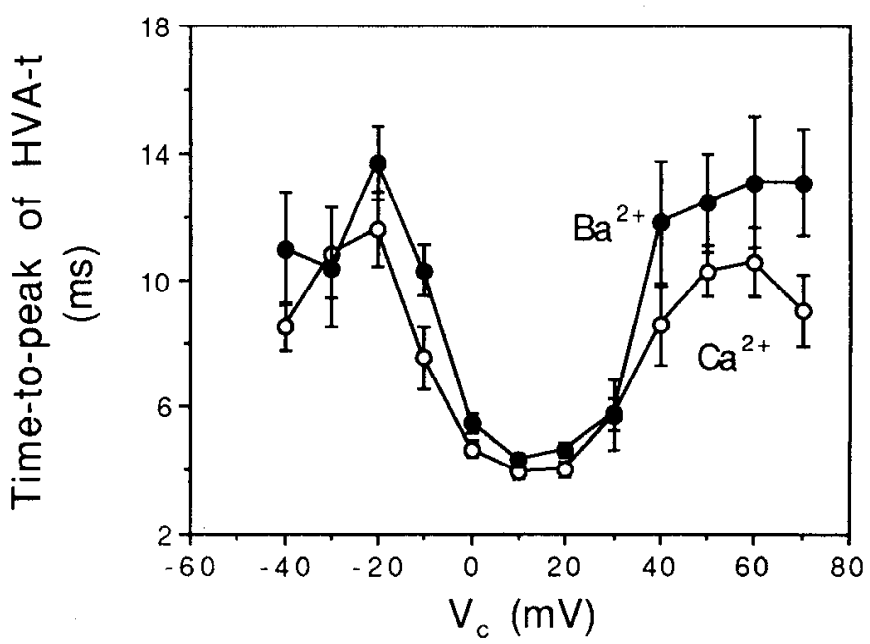

Figure 7. Time-to-peak $I_{\mathrm{Ca}}$ and $I_{\mathrm{Ba}}$, showing a U-shaped function of voltage, measured from data in Figure 5. Automatic peak detection software was used. Note the insignificantly but consistently longer $T_{\text {peak }}$ in barium relative to calcium. 

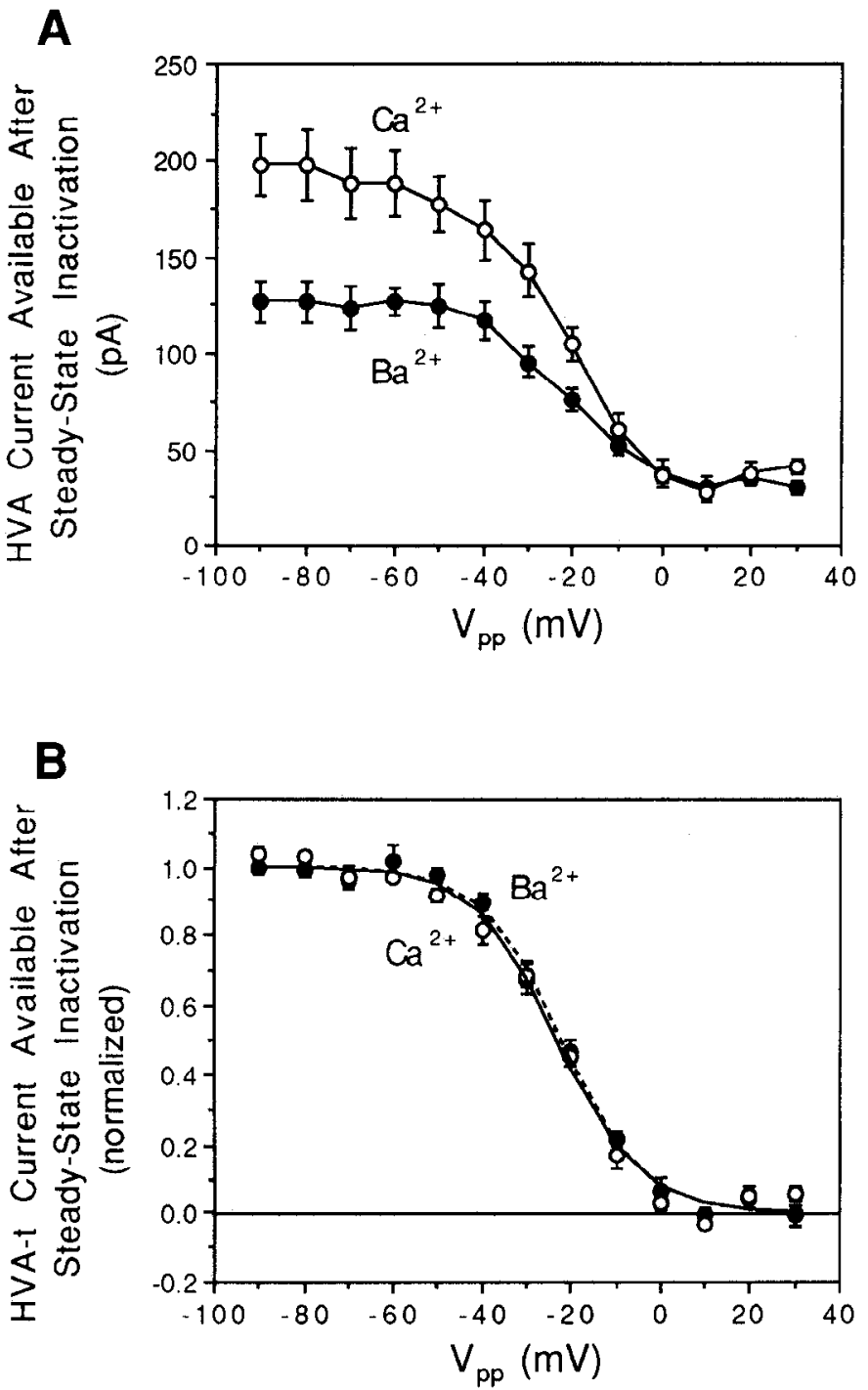

Figure 8. Availability of divalent cation current after pulses causing steady-state inactivation. One-second prepulses to different voltages $\left(V_{\mathrm{pD}}, a b s c i s s a\right)$ were applied from $-80 \mathrm{mV}$, followed immediately by a $35 \mathrm{msec}$ test pulse to $+10 \mathrm{mV}$. Open $\left(\mathrm{Ca}^{2+}\right)$ and solid $\left(\mathrm{Ba}^{2+}\right)$ circles are means $( \pm$ SEM) from six cells in calcium, seven in barium. $A$, Absolute calcium and barium test-pulse currents after steady-state inactivation
Table 3. Parameters used to fit Boltzmann curves to steady-state inactivation data for peak $I_{\mathrm{Ca}}$ and $I_{\mathrm{Ba}}$

\begin{tabular}{lrrl}
\multicolumn{1}{c}{$I_{\mathrm{Ca}}$} & \multicolumn{1}{l}{$I_{\mathrm{Ba}}$} & $P$ \\
\hline$V_{i}(\mathrm{mV})$ & $-23.4 \pm 1.5$ & $-22.0 \pm 1.0$ & $\mathrm{NS}$ \\
$K_{i}(\mathrm{mV})$ & $9.2 \pm 0.4$ & $8.7 \pm 0.7$ & $\mathrm{NS}$ \\
$I_{\max }(\mathrm{pA})$ & $-192.6 \pm 16.6$ & $-126.8 \pm 10.5$ & $0.001-0.01$ \\
$I_{\min }(\mathrm{pA})$ & $-31.2 \pm 3.8$ & $-30.8 \pm 4.0$ & $\mathrm{NS}$
\end{tabular}

Fitting was carried out on six $\left(I_{\mathrm{Ca}}\right)$ or seven $\left(I_{\mathrm{Ba}}\right)$ recordings from different cells, in each ionic condition. Average fitting parameters \pm SEM are presented. The equation fitted was $I_{\text {test }}=I_{\min }+\left(I_{\max }-I_{\min }\right) /\left\{1+\exp \left[\left(V_{\mathrm{pp}}-V_{\mathrm{j}}\right) / K_{i}\right]\right\} . I_{\text {eest }}$ was the peak current response to a test pulse following a $1 \mathrm{sec}$ prepulse to $V_{\text {mo }} I_{\text {min }}$ was the noninactivating component available at positive $V_{\mathrm{pp}}, I_{\max }$ was the maximal current available at negative $V_{\mathrm{pp}}, V_{i}$ was the voltage at half-inactivation, and $K_{i}$ was the steepness factor. For normalized curves, $I_{\min }$ was subtracted from $I_{\text {test }}$ and the difference was normalized to $\left(I_{\max }-I_{\min }\right)$.

\section{Pharmacology}

Experiments were carried out to test the sensitivity of divalent cation currents to pharmacological agents, namely cadmium, verapamil, and nifedipine.

Cadmium, applicd at concentrations of $0.08-1.3 \mathrm{~mm}$, grcatly reduced $I_{\mathrm{Ca}}$ responses to maximal depolarizations (Fig. 9A), although a small, residual, sustained current was present in five out of eight experiments. Cadmium insensitivity is usually associated with low-voltage-activated (LVA) currents (Durroux et al., 1988; Hernández-Cruz and Pape, 1989).

The slow and sustained tail currents seemed unaffected by cadmium, possibly because of release of $\mathrm{Cd}^{2+}$ block by hyperpolarization (Lansman et al., 1986). When current-clamp recordings were made in total-current conditions, application of $\mathrm{Cd}^{2+}$ removed the plateau phase of the action potential, indicating that some component of $I_{\mathrm{Ca}}$ underlies this phase of the

(prepulse response to $V_{\mathrm{po}}+10 \mathrm{mV}$ is shown in Fig. $3 \mathrm{C}$ ). Currents were measured with automatic peak detection, between $2.2 \mathrm{msec}$ and 9.2 msec from the beginning of the test pulse. Prepulse voltages are indicated on the abscissa. B. Availability of transient $I_{\mathrm{Ca}}$ and $I_{\mathrm{Ba}}$ as a function of $V_{\mathrm{pD}}$, after subtraction of the noninactivating component and normalization of the data to fitted, maximal test-pulse current. Solid $\left(\mathrm{Ca}^{2+}\right)$ and broken $\left(\mathrm{Ba}^{2+}\right)$ curves are Boltzmann distributions extracted from fits to the average, raw data in $A$.

Table 2. Parameters used to fit simulated $I-V$ functions to average data for peak $I_{C a}$ and $I_{\mathrm{Ba}}$

\begin{tabular}{lccl} 
& \multicolumn{1}{l}{$I_{\mathrm{Ca}}$} & $I_{\mathrm{B} a}$ & $P$ \\
\hline$V_{a, \mathrm{HV}}(\mathrm{mV})$ & $0.3 \pm 0.6$ & $3.0 \pm 1.2$ & $\mathrm{NS}$ \\
$K_{a, \mathrm{HV}}(\mathrm{mV})$ & $6.3 \pm 0.2$ & $6.4 \pm 0.4$ & $\mathrm{NS}$ \\
$P_{\text {max, HV }}($ liters$/ \mathrm{sec})$ & $(2.03 \pm 0.22) \times 10^{-13}$ & $(1.28 \pm 0.14) \times 10^{-13}$ & $0.01-0.02$ \\
$V_{a, \mathrm{VHV}}(\mathrm{mV})$ & $+80.5 \pm 4.7$ & $+66.0 \pm 10.2$ & $\mathrm{NS}$ \\
$K_{a, \mathrm{VHV}}(\mathrm{mV})$ & $10.7 \pm 0.8$ & $9.7 \pm 1.1$ & $\mathrm{NS}$ \\
$P_{\text {max.VHV }}($ liters$/ \mathrm{sec})$ & $(6.05 \pm 2.09) \times 10^{-12}$ & $(3.61 \pm 1.28) \times 10^{-12}$ & $\mathrm{NS}$
\end{tabular}

Data curves shown in Figure $4 A$. Data from each of nine cells in each ionic condition were fitted with a combination of the Goldman-Hodgkin-Katz (GHK) constant-field equation (Hille, 1984) and two Boltzmann distributions: $I_{D}=\left(P_{\mathrm{H}}\right.$ $\left.+P_{\text {vнV }}\right) \times Z^{2} F^{2} V / R T \times\left\{[D]_{i}-[D]_{o} \times \exp (-Z F V / R T)\right\} /\{1-\exp (-Z F V / R T)\}$, where $P_{\mathrm{Hv}}=P_{\max \mathrm{HV}} /\left\{1+\exp \left[\left(V_{\alpha \mathrm{HV}}\right.\right.\right.$ $\left.\left.-V) / K_{a, \mathrm{HY}}\right]\right\}$ and $P_{\mathrm{VHV}}=P_{\max , \mathrm{VHV}} /\left\{1+\exp \left[\left(V_{a, \mathrm{VHV}}-V\right) / K_{a, \mathrm{VHV}}\right]\right\}$. The variables were $V_{a}$, the voltage of half-activation, $K_{a}$ the steepness of the Boltzmann function, and $P_{\max }$, the maximal permeability to $\mathrm{Ca}^{2+}$ or $\mathrm{Ba}^{2+} . V_{a}$ and $K_{a}$ were fitted to the nearest $0.1 \mathrm{mV}, P_{\max }$ to the nearest $10^{-15}$ liters $/ \mathrm{sec}$. The constants were $[D]_{i}=10^{-9} \mathbf{M},[D]_{o}=10^{-2} \mathbf{M}, Z=2, F=$ $96480 \mathrm{C} / \mathrm{mol}, R=8314 \mathrm{mV} \times \mathrm{C}^{\circ} \mathrm{K} / \mathrm{mol}$, and $T=293^{\circ} \mathrm{K}$. A surface charge of zero was assumed in the GHK equation. At $V=0 \mathrm{mV}$ and negligible internal calcium, the GHK equation reduced to $I_{D(0)}=P_{n} \times Z F \times\left(-[D]_{m}\right)$. All fitting parameters were averaged over nine cells, except for VHV parameters in calcium $(N=8)$, which could not be fitted for one cell. Values are in mean \pm SEM. 

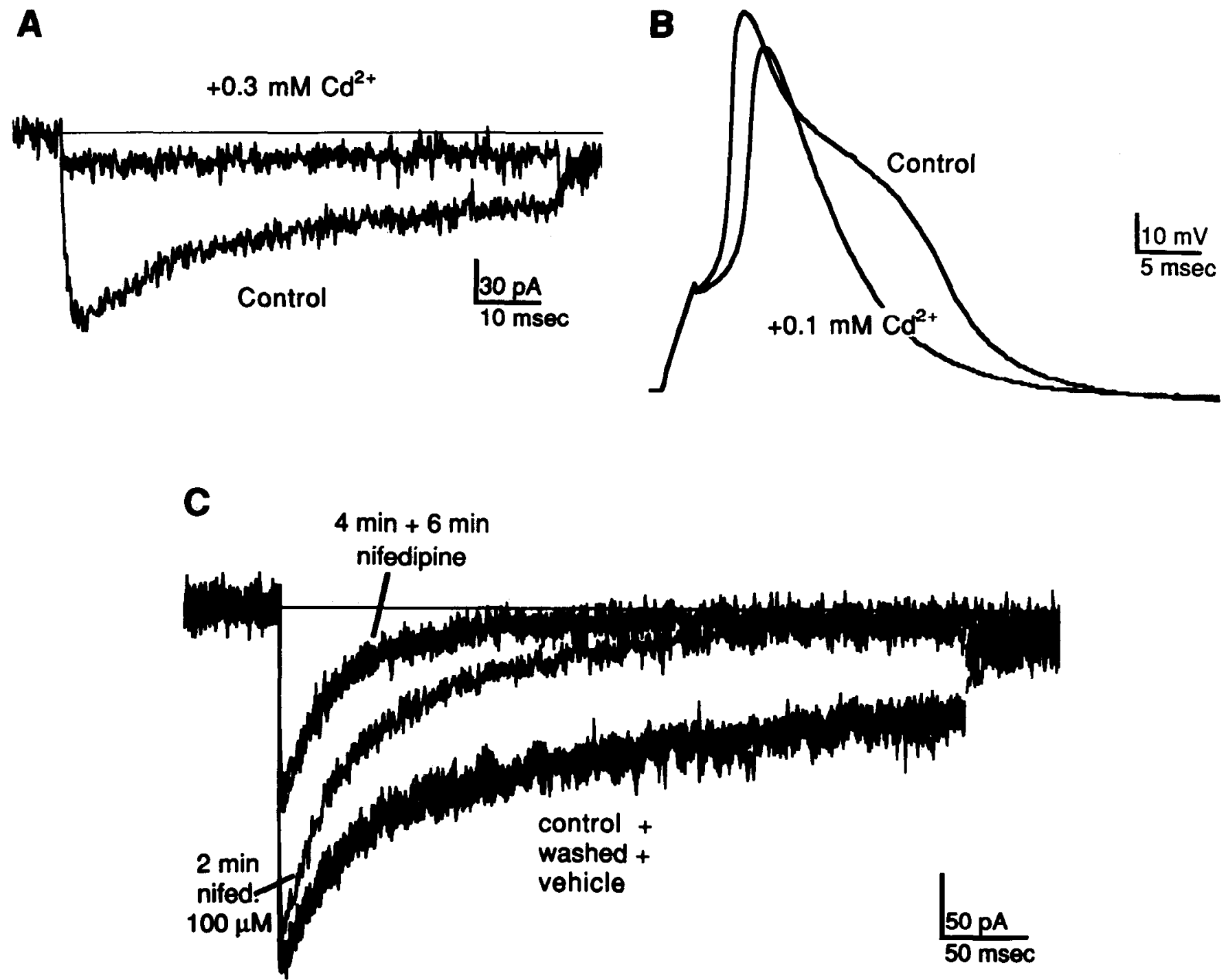

Figure 9. Pharmacology of the divalent cation currents. A, Representative trace showing nearly complete blockade of $I_{\mathrm{Ca}}$ by $0.3 \mathrm{~mm}$ Cd ${ }^{2+}$. The test pulse was applied from a $V_{h}$ of $-80 \mathrm{mV}$ to a $V_{c}$ of $+10 \mathrm{mV}$ just before and after 4 min of superfusion with $0.3 \mathrm{~mm} \mathrm{Cd}{ }^{2+}$. Sampling interval was $200 \mu \mathrm{sec}$. Subtraction protocol was $+p / 4$ from $-80 \mathrm{mV}$. B. Blockade of the action potential plateau by $0.1 \mathrm{~mm} \mathrm{Cd}^{2+}$. Sampling interval was $100 \mu$ sec. Bath solution contained (in mM) $\mathrm{NaCl}, 378 ; \mathrm{MgCl}_{2}, 29 ; \mathrm{CaCl}_{2}, 9.5 ; \mathrm{Na}_{2} \mathrm{SO}_{4}, 5.7 ; \mathrm{KCl}, 13.4 ; \mathrm{Cho}-\mathrm{Cl}, 42 ; \mathrm{HEPES}, 10 ;$ and $\mathrm{NaOH}, 5$. Clectrode solution contained (in $\mathrm{mM}$ ) $\mathrm{KCl}, 105 ; \mathrm{MgCl}_{2}, 2 ; \mathrm{CaCl}_{2}, 1$; HEPES, 10; EGTA, 11; dextrose, 740; and $\mathrm{KOH}, 35$. $C$, Nifedipine blockade of $I_{\mathrm{Ca}}$. Long test depolarizations ( $V_{h}=-80 \mathrm{mV} ; V_{c}=+10 \mathrm{mV}$ for $400 \mathrm{msec}$ ) were applied every minute during superfusions with $100 \mu \mathrm{M}$ nifedipine (vehicle: $0.05 \%$ DMSO + 0.9\% ethanol), normal saline, and vehicle-containing saline. Traces were taken 3 min before (initial), during ( 2 min and $4 \mathrm{~min}$ ), and $2 \mathrm{~min}$ after nifedipine superfusion $(6 \mathrm{~min}$ ), at the end of the washing period (washed), and 2 min after vehicle application (vehicle). After washing, the recording became unstable. After a period of rest at $V_{h}-40 \mathrm{mV}$, sufficient stability returned for vehicle application, which produced no change in peak $I_{\mathrm{C} 3}$ but spurious changes in late $I_{\mathrm{C}}$ (not shown). Note that control, washed, and vehicle traces coincide. Sampling interval was $500 \mu \mathrm{sec}$.

spike (Fig. 9B). The slower rising phase in $\mathrm{Cd}^{2+}$ also shows that HVA-t contributed to the rising phase of the spike.

Verapamil, dissolved in ethanol, did not produce any obvious effect when it was applied at 50-100 $\mu \mathrm{M}$, although only two such experiments were attempted.

Nifedipine, superfused at a concentration of $100 \mu \mathrm{M}$, consistently blocked the sustained component of $I_{\mathrm{Ca}}$ (Fig. $9 \mathrm{C}$ ) in a completely reversible manner. Blockade of the sustained current was more complete and more rapid than that of the peak, transient component. This differential blockade was seen in five out of six experiments, with only one case out of six showing little blockade. Application of the vehicle to one cell had no effect (Fig. 9C). When a double exponential was fitted to the current traces, it appeared that the sustained current ( $N=5 ; 80 \%$ block) was inhibited more effectively than the slowly inactivating exponential ( $N=3 ; 57 \%$ block), while the amplitude of the rapidly inactivating exponential was increased by $\sim 60 \%$. Neither the slow nor the fast time constant of inactivation seemed to change.

\section{Discussion}

Quality of the voltage clamp

The quality of the voltage clamp was assessed from passive and active responses. Capacitive transients on passive test pulses indicated the presence of a rapidly charging region of the cell clamped through a low-series-resistance pathway, and a slowly charging area of the cell membrane separated from the electrode 
tip by a high series resistance. For areas of the membrane nearest the electrode, the speed of clamping was satisfactory for peak current measurements, but it did not allow reliable measurement of events that were less than $0.5 \mathrm{msec}$ after the voltage transitions, that is, current activation time course and fast tail currents. The calculated series resistance error at peak current was negligible near the electrode $(-1.5 \mathrm{mV}$, maximum), so the voltages applied were very close to the desired command voltages. At more remote membrane sites, voltage pulses were probably rounded and attenuated by passive propagation.

The possible morphological basis for a region with high access resistance is interesting. SMNs in vitro presented a compact morphology with processes that, when present, were usually wide. The cytoplasm in these cells contains membranous inclusions (Spencer, 1979; Przysiezniak and Spencer, 1989) and deep infoldings of the plasmalemma. These membranes often show reflexive gap junctions (Spencer, 1979) and may create considerable access resistance, either internally by compartmentalizing the cell cytoplasm, or externally by restricting current flow from the bath to the membrane inside the infoldings (Keynes et al., 1973).

\section{The VHVA current}

The VHVA current behaved in a way that suggested it was being elicited at an electrotonically remote area of membrane, although no single piece of evidence directly demonstrates this. The slow onset of the VHVA current (Fig. $5 A, I_{\mathrm{Ba}}$ trace at +70 $\mathrm{mV}$ ) may have reflected an underlying voltage pulse rounded by conduction through a region of high resistance and membrane capacitance (see above discussion). While a calcium current with a slow onset is found in vertebrate skeletal muscle (Beaty et al., 1987; Bean, 1989), it is maximal at a much lower voltage (0 $\mathrm{mV}$ ). Maximal currents at very positive potentials are usually seen when the space clamp is nonuniform (Keynes et al., 1973; Stanley, 1989). Calcium currents at a large electrotonic distance would be activated by voltage pulses that appear very positive (e.g., $+50 \mathrm{mV}$ ) at the electrode tip but decay to more moderate levels (e.g., $+20 \mathrm{mV}$ ) at a distance.

It is unlikely that screening of the membrane surface charge by high concentrations of external divalent cations could account for the very positive voltage dependence of the VHVA current (Fig. 5B, Table 2) since screening would have caused a positive shift in the voltage dependence of all HVA channels, not just of a subset of channels. Furthermore, the onset of VHVA current was almost an order of magnitude slower than the slowest HVA current onset (Fig. $5 A$, compare $I_{\mathrm{Ba}}$ trace at $+70 \mathrm{mV}$ to trace at $-20 \mathrm{mV}$ ) so it is unlikely that the VHVA current represents an HVA current with a very-positively shifted voltage dependence.

Taken together, this evidence suggests that the VHVA current was carried through HVA channels located on an electrotonically remote area of the cell membrane, possibly membrane infoldings.

\section{The HVA currents}

Ionic selectivity

The calcium current was significantly larger than barium current at peak but not at the sustained level reached after $1 \mathrm{sec}$ of depolarization (Fig. 3C). The peaks of the inactivating $I_{\mathrm{Ca}}$ and $I_{\mathrm{Ba}}$ showed no significant differences in voltage dependencies of activation, time to peak, or inactivation (Figs. 6, 7, $8 B$, respectively), and there was no obvious difference in the time course of the tail currents (Fig. 3B). The functions fitted to the peak $I-$ $V$ data (Table 2) suggest that only macroscopic permeabilities differed between ionic species. These results indicate that the difference in peak $I_{\mathrm{Ba}}$ and $I_{\mathrm{Ca}}$ amplitudes does not reflect an ionselective effect on membrane surface charge, but may indicate selective permeability. A more subtle ion dependence of channel gating or flickering cannot be excluded, because we observe a consistent, though insignificant, lengthening of $T_{\text {peak }}$ for $I_{\mathrm{Ba}}$ relative to $I_{\mathrm{Ca}}$

Reports describing the effects of barium on calcium channel gating show many-fold shortenings of single-channel open or closed times (Nelson et al., .1984 , in rat channels; ChesnoyMarchais, 1985, in Aplysia patches) or dramatic lengthening of whole-cell current onset or tail current (Saimi and Kung, 1982, in Paramecium). We have not observed such dramatic effects, so the ionic selectivity measured in the HVA calcium currents of Polyorchis neurons likely arises not from differential channel gating, but from differential ion permeation.

The selective permeability of calcium channels to divalent cations is believed to depend on the binding affinities of different ions for certain sites on the channels (Almers and McCleskey, 1984; Hess and Tsien, 1984; Tsien et al., 1987; cf. Kostyuk et al., 1983). Blocking ions also bind to the same sites on the channels as do permeant ions, and a permeant ion with a strong binding affinity may act as a blocker when competing against another permeant ion of weaker binding affinity (Lansman et al., 1986). The permeability of a calcium channel to a certain ion depends therefore on the relative affinity of the channel binding sites for different cations present, on the concentrations of these ions around the channel, and on the interactions between these ions.

The ionic selectivity we observed could arise if impermeant magnesium ions, which occur at a high concentration in the bath $(40 \mathrm{~mm})$, were more effective in competing against barium than calcium for channel occupancy. The preferential inhibition by magnesium of $I_{\mathrm{Ba}}$ relative to $I_{\mathrm{Ca}}$ has been reported to occur (Ganitkevich et al., 1988). The existence of such a mechanism would be confirmed if selectivity were seen to reverse in the absence of extcrnal magnesium. The blockadc of a channel by magnesium ions can appear at the single-channel level as a flickering of the unitary current (Lansman et al., 1986). Because the kinetics of blocking and unblocking are usually more rapid than the closed and open gating kinetics, respectively, modulation of blockade may have only subtle effects on the time course of macroscopic current activation and deactivation, but may affect the mean amplitude of whole-cell current dramatically. Our results exhibit a dramatic, ion-dependent difference in current amplitude (Fig. $3 A$ ) accompanied by a subtle difference in the kinetics of activation (Fig. 7).

Another possible mechanism is that residual calcium, leached from the electrode glass into the bath (Furman and Tanaka, 1988; Copello et al., 1991), may have inhibited $I_{\mathrm{Ba}}$ because of its higher affinity for calcium channels, compared to that of barium. This mechanism does not preclude the action of the magnesium blockade described above. Alternately, the binding affinity of calcium might have been weaker than that of barium, allowing a faster transit time and a larger current of calcium than of barium. However, most other works report a greater affinity of calcium than barium (cf. Almers and McCleskey, 1984; Hess and Tsien, 1984; Lansman et al., 1986; Ganitkevich et al., 1988). In summary, we suspect that the ionic selectivity we see is due to magnesium competing differentially with cal- 
cium and barium, although calcium leaching from the electrode glass could also have a similar effect.

The absence of ionic selectivity of the sustained current may have resulted from the reduction of apparent $I_{\mathrm{Ca}}$ by contamination with a slow, outward current that was blocked in barium. However, such an effect is unlikely to have occurred because it would have had to compensate exactly for the differences between sustained $I_{\mathrm{Ca}}$ and $I_{\mathrm{Ba}}$ throughout the voltage range studied (Fig. 4B). Similarly, relief from calcium-dependent inactivation may have caused sustained $I_{\mathrm{Ba}}$ to be larger and more similar to $I_{\mathrm{Ca}}$ than expected, but this effect would likely not occur with such exactness throughout the voltage range studied. Thus, the difference in ionic selectivity between the HVA-t and HVA-s currents probably reflected the selectivities of the underlying calcium channels.

The nonselective, sustained current might flow through a single population of inactivating channels, which inactivate incompletely and change their selectivity in the process. Incomplete inactivation of a single channel population has been reported frequently (Chad et al., 1984; Hennessey and Kung, 1985; Swandulla and Armstrong, 1988; Jones and Marks, 1989; Plummer et al., 1989; Plummer and Hess, 1991; Slesinger and Lansman, $1991 \mathrm{a}, \mathrm{b})$. However, in no case has a change in ionic selectivity with inactivation been studied or observed. It is more likely that HVA-s current flows through a noninactivating, nonselective channel population distinct from that mediating the HVA-t current. The coexistence of separate channel populations with distinct inactivation kinetics and/or ionic selectivities occurs frequently (McCleskey et al., 1986; Yaari et al., 1987; Durroux et al., 1988; Hernández-Cruz and Pape, 1989; Carbone et al., 1990; Regan, 1991), although in no case has the particular combination described here been observed. Usually, sustained current is selective for barium over calcium (L-type channels), and the transient component is nonselective (HVA or "N") or selective for calcium over barium (LVA or "T").

Experiments involving manipulations of calcium and barium concentrations, pharmacology and/or single-channel recordings will be necessary to clarify the mechanism of ionic selectivity and the identity of the transient and sustained current components.

\section{Inactivation}

The inactivation of the calcium current may have resulted from a current-dependent or a voltage-dependent mechanism. Current-dependent inactivation specific for calcium ions was unlikely to occur in the conditions used because both $I_{\mathrm{Ca}}$ and $I_{\mathrm{Ba}}$ showed identical voltage dependencies of inactivation (Table 3 , Fig. $8 B$ ). As mentioned above, relief from calcium-dependent inactivation was unlikely to produce a slowing of the slowly inactivating $I_{\mathrm{Ba}}$ relative to $I_{\mathrm{Ca}}$ (Table 1 , Fig. $3 \mathrm{C}$ ) because of the coincidences this would involve. In addition, calcium-dependent inactivation usually affects rapid decay more readily than it does slow inactivation (Hennessey and Kung, 1985; Habuchi et al., 1990; Plummer et al., 1990). Mechanisms for calciumdependent inactivation may have been present but undetectable under the conditions used because of buffering by EGTA in the electrode solution.

On the other hand, huffering by intracellular FGTA may have been too slow to inhibit a divalent-cation-dependent mechanism in SMNs, and current-dependent inactivation may have occurred. Chad et al. (1984) have proposed a model of calciumdependent inactivation that may be applied to less specific mechanisms of current-dependent inactivation. They surmise that a complex time course of decay showing two exponentials and incomplete inactivation may result if the proportion of channels available for opening decays hyperbolically with increasing submembranous $\left[\mathrm{Ca}^{2+}\right]_{i}$. Thus, rapid decay would result from the initial influx of divalent cations raising submembranous $\left[\mathrm{Ca}^{2+}\right]_{i}$ to a level at which the mechanism causing inactivation is most sensitive. The more slowly decaying component would appear when the inactivation mechanism becomes saturated and responds with less sensitivity. Finally, the sustained component would occur at a level where calcium influx is balanced by calcium removal, and little submembranous calcium remains to elicit inactivation. The sustained current would therefore depend on the amount of intracellular divalent cation buffering and would be reduced by experimentally decreasing the buffering capacity of the cytosol.

The steady-state inactivation curve shows considerable inactivation at voltages where little current is elicited on the prepulse (compare Figs. $4 A, 8 B$ ). If current-dependent inactivation were present, as described above, a small influx would increase submembranous divalent cation concentration to within the steep, dynamic range of the inactivation mechanism, while much larger influx would elicit saturating inactivation. Depending on the capacity of the inactivation mechanism for bound divalent cations, and on the intracellular buffering, maximal inactivation will occur after different amounts of influx. Thus, the general lack of recovery from inactivation at positive prepulses, where a small but significant influx occurs, may indicate that the inactivation mechanism has a low capacity for divalent cations, or that the intracellular divalent cation buffer is saturated.

A mechanism of voltage-dependent inactivation can also produce features such as a complex time course of inactivation with incomplete inactivation, and significant inactivation at nonactivating voltages. A double-exponential decay would result if a single channel population mediating only the HVA-t current showed two inactivated states reached by pathways with different rate constants. Alternately, if both the selective, HVA-t and nonselective, HVA-s currents were mediated by a single population of channels, then it would be necessary to invoke a gating mechanism involving two open states with different ionic selectivities and possibly an inactivated state from which channels can reopen to the nonselective state, giving the sustained current. Some combination of rate constants between the two open states and the inactivated state could produce a double-exponential decay. By its simplicity, the first mechanism seems more likely.

Inactivation at voltages where few channels are activated could occur if channels can convert directly from the closed to the inactivated state, in a voltage-dependent manner. At activating voltages, inactivation likely occurs indirectly, via the activated states. Recovery from inactivation may also occur through the open state and may be visible as a reopening tail current in responses to sudden repolarizations (Slesinger and Lansman, $1990,1991 \mathrm{c})$. In SMNs, repolarizations to $-80 \mathrm{mV}$ produced slow and sustained tail currents that were selective for $\mathrm{Ca}^{2+}$ over $\mathrm{Ba}^{2+}$ (Fig. $3 B$ ), and may have arisen from reopenings of channels carrying the ion-selective HVA-t current. Repolarizations to $-40 \mathrm{mV}$ only elicited tail currents lasting less than $2 \mathrm{msec}$, with no sign of a sustained tail current, suggesting that recovery from inactivation at this voltage was mostly through transitions from inactivated to closed states. The inactivation and recovery from inactiviation of the calcium channels may have occurred via 
direct and/or indirect pathways, and the relative contribution of each pathway to these processes remains to be determined. Much of the voltage dependence of inactivation may arise from the voltage dependence of transitions from the closed to the open or inactivated states. According to this model, transitions between open and inactivated states don't have to be voltage dependent.

Experimental manipulations of intracellular divalent cation buffering and single-channel recordings should help determine which particular mechanism of current- or voltage-dependent inactivation is at work in the SMNs of Polyorchis. Both mechanisms could contribute to this process (e.g., Brehm et al., 1980; Hennessey and Kung, 1985; Gutnick et al., 1989; Habuchi et al., 1990).

\section{Nifedipine blockade}

At the large concentration of nifedipine used $(100 \mu \mathrm{M})$, the inhibitory effect of this drug on both the nonselective, sustained and the selective, slowly inactivating components suggests that the action was nonspecific. Dihydropyridines are known to bind to calcium channels while they are open, producing an apparent inactivation (Lee and Tsien, 1983; Sanguinelti and Kass, 1984). This could spare the rapidly inactivating component, and block the slowly inactivating component more than the sustained current, as was observed. This result does not conclusively indicate how many HVA calcium channels are present in the membrane of Polyorchis SMNs.

\section{Conclusions on the HVA currents}

In summary, it is probable that there are two HVA channel populations in SMNs of this jellyfish. The major objection to the existence of a single population of HVA channels is that whole-cell current would have to change from being ion selective before inactivation to nonselective after inactivation. There are no reports in the literature indicating that ionic selectivity depends on the state of inactivation of a channel.

These experiments have not provided sufficient evidence to demonstrate the predominance of either current- or voltagedependent inactivation mechanisms of the HVA calcium currents.

\section{Functions of the calcium currents}

The calcium currents in SMNs of Polyorchis penicillatus play important roles in excitability and synaptic transmission in the electrically coupled network of the SMNs. The high voltage of activation of these currents indicates they may accompany the sodium current (Przysiezniak and Spencer, unpublished observations) in producing the relatively high spiking threshold found in these cells $\left(V_{m} \sim-20 \mathrm{mV}\right)$. The sensitivity to $\mathrm{Cd}^{2+}$ of the rising slope of the action potential (Fig. $9 B$ ) indicates the rapidly activating HVA-t may participate in the spike upstroke. HVA-s may contribute to the slow, spontaneous, membrane potential fiuctuations observed in vitro (Przysiezniak and Spencer, unpublished observations).

Cadmium blockade of the action-potential plateau phase (Fig. $9 B$ ) indicates another role for the calcium current, probably associated with synaptic transmission (Spencer et al., 1989). The plateau duration changes consistently with baseline membrane voltage and the distance of spike propagation around the electrically coupled network of the SMNs (Spencer and Satterlie, 1980; Spencer, 1982). This is associated with changes in synaptic delay at the SMN-swim muscle junction that compensate for propagation time of the action potentials around the bell and synchronize contraction of all regions of the swimming bell. Understanding the relative contributions of HVA-t and HVA-s currents to this phenomenon awaits further pharmacological characterization.

While the SMNs have been studied most extensively in this jellyfish, other cells are also present that show different suites of voltage-dependent ionic currents. Neurons producing shortduration spikes in vitro are smaller than SMNs and more "neuron-like" (with distinct soma and neurites; Przysiezniak and Spencer, 1989), and their activity resembles that of the identified "B" or "burster" neurons observed in semidissected preparations (Arkett and Spencer, 1986). These cells showed very little calcium current, if any, in response to depolarizations from a holding potential of $-80 \mathrm{mV}$ to $+10 \mathrm{mV}$ (Przysiczniak and Spencer, unpublished observations), which explains the absence of a spike plateau. In situ, myoepithelial cells produce plateau action potentials lasting about $170 \mathrm{msec}$ (Spencer and Satterlie, 1981 ), arising from a negative resting potential $(-75 \mathrm{mV}$; Spencer and Satterlie, 1981). Tetraethylammonium application lengthened the plateau phase (Spencer and Satterlie, 1981) of in vivo myoepithelial spikes. Such spikes may be maintained by a small, sustained calcium current and repolarized by a slowly arising potassium current. This type of calcium current also appears to be present in SMNs. Thus, the "repertoire" of calcium currents observed in SMNs is obviously specific to that cell type, but may be partly shared by other cells.

\section{Taxonomic and evolutionary considerations}

Recordings of calcium currents in jellyfish, anemones, and their kin are recently becoming more common. Anderson (1987) demonstrated the presence of an HVA, rapidly activating $\left(T_{\text {peak }}\right.$ $\sim 2 \mathrm{msec}$ ) and inactivating calcium current in neuronal somata of the scyphozoan jellyfish Cyanea capillata, which, with a fast sodium current, contributes to produce a short-duration spike. Recorded in high concentrations of external calcium (95 mM), this current was maximal at $+35 \mathrm{mV}$. In normal calcium concentrations, the maximum current would likely occur at more negative voltages because of surface charge unscreening, making the voltage dependence more similar to that of Polyorchis currents. Dunlap et al. (1987) describe a calcium current in epithelial cells of a colonial hydroid, Obelia. This current serves as a source of calcium for bioluminescence in photocytes that are coupled through gap junctions to these epithelial cells. It activates slowly ( $\left.T_{\text {peak }} \sim 60 \mathrm{msec}\right)$, inactivates slowly, and reaches a maximum around $-5 \mathrm{mV}$ in $40 \mathrm{~mm}$ barium. At more natural calcium concentrations, the $I-V$ curve might be shifted to more negative voltages, as for an LVA current. Meech (1989) briefly describes a calcium current in the hydrozoan jellyfish Aglantha digitale, which activates rapidly, at low voltages. Most recently, Holman and Anderson (1991) have presented evidence for an inactivating calcium current in myoepithelial cells of the anemone Calliactis tricolor resembling the HVA current we have observed. This current has the permeability sequence $\mathrm{Ca}^{2}$ + $>\mathrm{Sr}^{2+}>\mathrm{Ba}^{2+}$, which is similar to that described here for the HVA-t current. While no LVA current could be clearly identified in the SMNs of Polyorchis, the small cadmium-insensitive current (Fig. 9A) may indicate its presence.

The HVA calcium currents of Polyorchis penicillatus share features with the three common classes of vertebrate calcium currents. Rapid activation and inactivation, and activation at relatively depolarized voltages make the HVA-t component 
similar to the N-current (Nowycky et al., 1985; McCleskey et al., 1986). However, a positive voltage range of inactivation, as seen here, is not a feature of $\mathrm{N}$-currents, and neither is selectivity for calcium over barium, which has usually been described in transient, LVA, T-channels (Durroux et al., 1988; Akaike et al., 1989; Hernández-Cruz and Pape, 1989). Interestingly, HVA currents in marine tunicate eggs are larger in calcium than barium (Okamoto et al., 1976), like the HVA-t current observed here. The HVA-s component behaved like the L-current; it activated in a positive voltage range, inactivated slowly, if at all, and showed little steady-state inactivation at positive voltages (although $1 \mathrm{sec}$ prepulses may be too short to see this). However, its lack of ionic selectivity makes it more similar to the T- or N-currents than to the L-current (Durroux et al., 1988; Hirano et al., 1989; cf. Johansen et al., 1987). The absence of rundown of the HVA currents in Polyorchis makes them dissimilar from the HVA currents in vertebrates, and more similar to the LVA, T-current (Durroux et al., 1988; Akaike et al., 1989). Insensitivity to blockade by dihydropyridines is not uncommon among invertebrate phyla (Ehrlich et al., 1988).

It appears that cnidarians can exhibit both LVA and HVA calcium currents. Two types of voltage-gated calcium channel, distinguished by their voltage ranges of activation, can also be recorded from the protozoan Stylonychia (Deitmer, 1984), the snail Helisoma (Haydon and Man-Son-Hing, 1988), and many vertebrate cells (see above). It is possible that protists, cnidarians, and other animals have evolved so much from their original ancestors that little evidence remains of the primitive traits of calcium channels among extant species. Thus, the present classes of LVA and HVA channels may have arisen several times in evolution, under the biophysical constraints requiring a calcium channel to regulate activity near the resting potential (LVA) and another channel acting more occasionally and briefly during periods of excitation (HVA). Alternately, the divergence of calcium channels into I.VA and HVA classes may have occurred at an early stage of evolution, and would have determined the basic molecular structure of these channel types in extant metazoans. If this were the case, it is likely that the differences in amino acid sequence between these two classes of channels would be more important than the molecular differences between channel types within each class. Molecular studies have already suggested that sodium channels have arisen from primitive HVA calcium channels (Hille, 1984; Catterall, 1988), indicating this class of calcium channel may be relatively primitive. The amino acid sequences of HVA channels show much similarity within this class (Perez-Reyes et al., 1990; Mori et al., 1991; Snutch et al., 1991). However, a more satisfying conclusion regarding the evolutionary divergence of calcium channels will require a molecular description of LVA channels.

\section{References}

Akaike N, Kostyuk PG, Osipchuk YV (1989) Dihydropyridine-sensitive low-threshold calcium channels in isolated rat hypothalamic neurones. J Physiol (Lond) 412:181-195.

Almers W, McCleskey EW (1984) Non-selective conductance in calcium channels of frog muscle: calcium selectivity in a single-file pore. J Physiol (Lond) 353:585-608.

Anderson PAV (1979) Ionic basis of action potentials and bursting activity in the hydromedusan jellyfish Polyorchis penicillatus. J Exp Biol 78:299-302.

Anderson PAV (1987) Propertics and pharmacology of a TTX-insensitive $\mathrm{Na}^{+}$current in neurones of the jellyfish, Cyanea capillata. J Exp Biol 133:231-248.
Andcrson PAV, Mackie GO (1977) Electrically coupled, photosensitive neurones control swimming in a jellyfish. Science 197:186-188. Arkett SA, Spencer AN (1986) Neuronal mechanisms of a hydromedusan shadow reflex. I-Identified reflex components, and sequence of events. J Comp Physiol A 159:201-213.

Bean BP (1989) Classes of calcium channels in vertebrate cells. Annu Rev Physiol 51:367-384.

Beaty GN, Cota G, Nicola Siri L, Sanchez JA, Stefani E (1987) Skeletal muscle $\mathrm{Ca}^{2+}$ channels. In: Structure and physiology of the slow inward calcium channel, Vol 1 (Triggle DJ, Venter JC, eds), pp 123-140. New York: Liss.

Brehm P, Eckert R, Tillotson D (1980) Calcium-mediated inactivation of calcium current in Paramecium. J Physiol (Lond) 306:193-203.

Carbone E, Sher E, Clementi F (1990) Ca currents in human neuroblastoma IMR 32 cells: kinetics, pcrmcability and pharmacology. Pfluegers Arch 416:170-179.

Catterall WA (1988) Structure and function of voltage-sensitive ion channels. Science 242:50-61.

Chad J, Eckert R, Ewald D (1984) Kinetics of calcium-dependent inactivation of calcium current in voltage-clamped neurones of Aplysia californica. J Physiol (Lond) 347:279-300.

Chesnoy-Marchais D (1985) Kinetic properties and selectivity of calcium-permeable single channels in Aplysia neurones. J Physiol (Lond) 367:457-488.

Copello J, Simon B, Segal Y, Wehner F, Ramanujam VMS, Alcock N, Reuss L (1991) $\mathrm{Ba}^{2+}$ release from soda glass modifies single maxi $\mathrm{K}^{+}$channel activity in patch clamp experiments. Biophys $\mathrm{J} \mathrm{60:931-}$ 941.

Deitmer JW (1984) Evidence for two voltage-dependent calcium currents in the membrane of the ciliate Stylonychia. J Physiol (Lond) 355:137-159.

Dunlap K, Takeda K, Brehm P (1987) Activation of a calcium-dependent photoprotein by chemical signalling through gap junctions. Nature 325:60-62.

Durroux T, Gallo-Payet N, Payet MD (1988) Three components of the calcium current in cultured glomerulosa cells from rat adrenal gland. J Physiol (Lond) 404:713-729.

Ehrlich BE, Jacobson AR, Hinrichsen R, Sayre LM, Forte MA (1988) Paramecium calcium channels are blocked by a family of calmodulin antagonists. Proc Natl Acad Sci USA 85:5718-5722.

Furman RE, Tanaka JC (1988) Patch electrode glass composition affects ion channel currents. Biophys J 53:287-292.

Ganitkevich VY, Shuba MF, Smimov SV (1988) Saturation of calcium channels in single isolated smooth muscle cells of guinea-pig taenia caeci. J Physiol (Lond) 399:419-436.

Gutnick MJ, Lux HD, Swandulla D, Zucker H (1989) Voltage-dependent and calcium-dependent inactivation of calcium channel current in identified snail neurones. J Physiol (Lond) 412:197-220.

Habuchi Y, Noda T, Nishimura M, Watanabe Y (1990) Recovery of the slow inward current from $\mathrm{Ca}^{2+}$-mediated and voltage-dependent inactivation in the rabbit sinoatrial node. J Mol Cell Cardiol 22:469 482.

Haydon PG, Man-Son-Hing H (1988) Low- and high-voltage-activated calcium currents: their relationship to the site of neurotransmitter release in an identified neuron of Helisoma. Neuron 1:919927.

Hennessey TM, Kung C (1985) Slow inactivation of the calcium current of Paramecium is dependent on voltage and not internal calcium. J Physiol (Lond) 365:165-179.

Hernández-Cruz A, Pape H-C (1989) Identification of two calcium currents in acutely dissociated neurons from the rat lateral geniculate nucleus. J Neurophysiol 61:1270-1283.

Hess P, Tsien RW (1984) Mechanism of ion permeation through calcium channels. Nature 309:453-456.

Hille B (1984) Ionic channels of excitable membranes. Sunderland, MA: Sinauer.

Hirano Y, Fozzard HA, January CT (1989) Inactivation properties of T-type calcium current in canine cardiac Purkinjc cclls. Biophys J 56: 1007-1016.

Holman MA, Anderson PAV (1991) Voltage-activated ionic currents in myoepithelial cells isolated from the sea anemone Calliactis tricolor. J Exp Biol 161:333-346.

Johansen J, Yang J, Kleinhaus AL (1987) Voltage-clamp analysis of the ionic conductances in a leech neuron with a purely calcium-dependent action potential. J Neurophysiol 58:1468-1484. 
Jones SW, Marks TN (1989) Calcium currents in bullfrog sympathetic neurons. II. Inactivation. J Gen Physiol 94:169-182.

Keynes RD, Rojas E, Taylor RE, Vergara J (1973) Calcium and potassium systems of a giant barnacle muscle fibre under membrane potential control. J Physiol (Lond) 229:409-455.

Kostyuk PG, Mironov SL, Shuba YM (1983) Two ion-selecting filters in the calcium channel of the somatic membrane of mollusc neurons. J Membr Biol 76:83-93.

Lansman JB, Hess P, Tsien RW (1986) Blockade of current through single calcium channels by $\mathrm{Cd}^{2+}, \mathrm{Mg}^{2+}$, and $\mathrm{Ca}^{2+}$. Voltage and concentration dependence of calcium entry into the pore. J Gen Physiol 88:321-347.

Lee KS, Tsien RW (1983) Mechanisms of calcium channel blockade by verapamil, D600, diltiazem and nitrendipine in single dialysed heart cells. Nature 302:790-794.

Lux HD, Carbone D, Zucker $\mathrm{H}$ (1990) $\mathrm{Na}^{+}$currents through lowvoltage-activated $\mathrm{Ca}^{2+}$ channels of chick sensory neurones: block by external $\mathrm{Ca}^{2+}$ and $\mathrm{Mg}^{2+}$. J Physiol (Lond) 430:159-188.

McCleskey EW, Fox AP, Feldman D, Tsien RW (1986) Different types of calcium channels. J Exp Biol 124:177-190.

Meech RW (1989) The electrophysiology of swimming in the jellyfish Aglantha digitale. In: Evolution of the first nervous systems (Anderson PAV, ed), pp 281-298. New York: Plenum.

Meves $H$, Vogel W (1973) Calcium inward currents in internally perfused giant axons. J Physiol (Lond) 235:225-265.

Mori Y, Friedrich T, Kim M-S, Mikami A, Nakai J, Ruth P, Bosse E, Hofmann F, Flockerzi V, Furuichi T, Mikoshiba K, Imoto K, Tanabe $T$, Numa S (1991) Primary structure and functional expression from complementary DNA of a brain calcium channel. Nature 350:398402.

Nelson MT, French RJ, Krueger BK (1984) Voltage-dependent calcium channels from brain incorporated into planar lipid bilaycrs. Nature 308:77-80.

Nowycky MC, Fox AP, Tsien RW (1985) Three types of neuronal calcium channel with different calcium agonist sensitivity. Nature 316:440-443.

Okamoto H, Takahashi K, Yoshii M (1976) Two components of the calcium current in the egg cell membrane of the tunicate. J Physiol (Lond) 255:527-561.

Perez-Reyes E, Wei X, Castellano A, Birnbaumer L (1990) Molecular diversity of L-type calcium channels. Evidence for alternative splicing of the transcripts of three non-allelic genes. J Biol Chem 265:2043020436.

Plummer MR, Hess P (1991) Reversible uncoupling of inactivation in N-type calcium channels. Nature 351:657-659.

Plummer MR, Logothetis DE, Hess P (1989) Elementary propertics and pharmacological sensitivities of calcium channels in mammalian peripheral neurons. Neuron 2:1453-1463.

Plummer MR, Kanevsky M, Hess P (1990) Multiple forms of inactivation of the N-type calcium current. Soc Neurosci Abstr 16:622.

Przysiezniak J, Spencer AN (1989) Primary culture of identified neurones from a cnidarian. J Exp Biol 142:97-113.

Regan LJ (1991) Voltage-dependent calcium currents in Purkinje cells from rat cerebellar vermis. J Neurosci 11:2259-2269.
Saimi Y, Kung C (1982) Are ions involved in the gating of calcium channels? Science 218:153-156.

Sanguinetti MC, Kass RS (1984) Voltage-dependent block of calcium channel current in the calf cardiac Purkinje fiber by dihydropyridine calcium channel antagonists. Circ Res 55:336-348.

Satterlie RA, Spencer AN (1983) Neuronal control of locomotion in hydrozoan medusae. A comparative study. J Comp Physiol A 150: 195-206.

Slesinger PA, Lansman JB (1990) Calcium channel reopenings at resting membrane potentials following prior depolarization. Soc Neurosci Abstr 16:1174.

Slesinger PA, Lansman JB (1991a) Inactivation of calcium currents in granule cells cultured from mouse cerebellum. J Physiol (Lond) 435:101-121.

Slesinger PA, Lansman JB (199\% b) Inactivating and non-inactivating dihydropyridine-sensitive $\mathrm{Ca}^{2+}$ channels in mouse cerebellar granule cells. J Physiol (Lond) 439:301-323.

Slesinger PA, Lansman JB (1991c) Reopening of calcium channels at negative membrane potentials depends on channel inactivation. Biophys $\mathrm{J}$ 59:537a.

Snutch TP, Tomlinson WJ, Leonard JP, Gilbert MM (1991) Distinct calcium channels are generated by alternative splicing and are differentially expressed in the mammalian CNS. Neuron 7:45-57.

Sokal RR, Rohlf FJ (1981) Biometry, 2d ed. New York: Freeman.

Spencer AN (1978) Neurobiology of Polyorchis. I. Function of effector systems. J Neurobiol 9:143-157.

Spencer AN (1979) Neurobiology of Polyorchis. II. Structure of effector systems. J Neurobiol 10:95-117.

Spencer AN (1981) The parameters and properties of a group of electrically coupled neurones in the central nervous system of a hydrozoan jellyfish. J Expl Biol 93:33-50.

Spencer AN (1982) The physiology of a coelenterate neuromuscular synapse. J Comp Physiol A 148:353-363.

Spencer AN, Satterlie RA (1980) Electrical and dye coupling in an identified group of neurones in a coelenterate. J Neurobiol 11:13-19.

Spencer AN, Satterlie RA (1981) The action potential and contraction in subumbrellar swimming muscle of Polyorchis penicillatus (Hydromedusae). J Comp Physiol 144:401-407.

Spencer AN, Przysiezniak J, Acosta-Urquidi J, Basarsky TA (1989) Presynaptic spike broadening reduces junctional potential amplitude. Nature 340:636-638.

Stanley EF (1989) Calcium currents in a vertebrate presynaptic nerve terminal: the chick ciliary ganglion calyx. Brain Res 505:341-345

Stockbridge NL (1987) EGTA. Comput Biol Med 17:299-304.

Swandulla D, Armstrong CM (1988) Fast-deactivating calcium channels in chick sensory neurons. J Gen Physiol 92:197-218.

Tsien RW, Hess P, McCleskey EW, Rosenberg RL (1987) Calcium channels: mechanisms of selectivity, permeation and block. Annu Rev Biophys Biophys Chem 16:265-290.

Yaari Y, Hamon B, Lux HD (1987) Development of two types of calcium channels in cultured mammalian hippocampal neurons. Science 235:680-682. 